\title{
Micro Abrasive-Waterjet Technology
}

\author{
H.-T. Liu and E. Schubert \\ OMAX Corporation, \\ USA
}

\section{Introduction}

Waterjet technology has come a long way since its commercialization in the late 1970 's. ${ }^{1}$ It has evolved from merely a rough cutting tool to a precision machine tool, competing on equal footing with established tools such as lasers, mechanical milling and routing tools, EDM, ultrasonics, photochemical etching, and various CNC tools.

The versatile waterjet technology inherently has advantages unmatched by most machine tools. Below is a short list of these advantages.

- Cuts virtually any material, thin and thick

- Fast setup and programming - modern systems are now easy to learn

- $\quad$ Simple fixturing is required - negligible reactionary forces on parts

- Almost no heat generation during cutting - no heat-affected zone (HAZ) on parts

- No residual mechanical stresses

- Safe operations

- No start hole required - one single tool for multi-mode machining

- Narrow kerf - removal of only a small amount of material

- Cost-effective and fast turnaround for both small and large lots

- Environmentally friendly - no hazardous waste byproducts

Figure 1 shows a typical abrasive-waterjet system along with a closeup of a nozzle and representative AWJ-cut parts made of various materials. The advantages and disadvantages of AWJs in comparison with lasers, EDM, plasma, flame cutting, and milling can be found in waterjets.org. ${ }^{2}$ Waterjet technology has been adopted rapidly in the manufacturing industry to take advantage of its technological and manufacturing merits. ${ }^{3}$ Waterjets can be used to machine noncritical components ready for assembly. For critical components requiring highprecision machining, waterjets have been used extensively as a net-shape tool, particularly for difficult-to-machine materials such as hardened steels, alloys, ceramics, and silicon carbide ceramic matrix composites. The versatility of waterjet technology has led to a broad

\footnotetext{
${ }^{1}$ Waterjet technology generally refers to the use of any of three jets: a water-only jet (WJ), an abrasivewaterjet (AWJ), or an abrasive slurry or suspension jet (ASJ) (Momber \& Kovacevic, 1998, Fig. 1.1). For conciseness, the term waterjets is used to refer to all three types of jets unless specified otherwise. $2 \mathrm{http}: / /$ waterjets.org/index.php?option=com_content\&task=category\&sectionid $=4 \& \mathrm{id}=46 \&$ Itemid= 53\#advantages_of_waterjet_machining (8 August 2011).

${ }_{3}^{3}$ Waterjet machine tools emerged as the fastest growing segment of the overall machine tool industry in the last decade, and this trend is expected to continue (Frost and Sullivan - "The World Waterjet Cutting Tools Markets" Date Published: 30 Aug 2005 (www.frost.com).
} 
range of capabilities from macro- to micromachining in most materials, which is unmatchable by most machine tools (Liu \& McNiel, 2010).

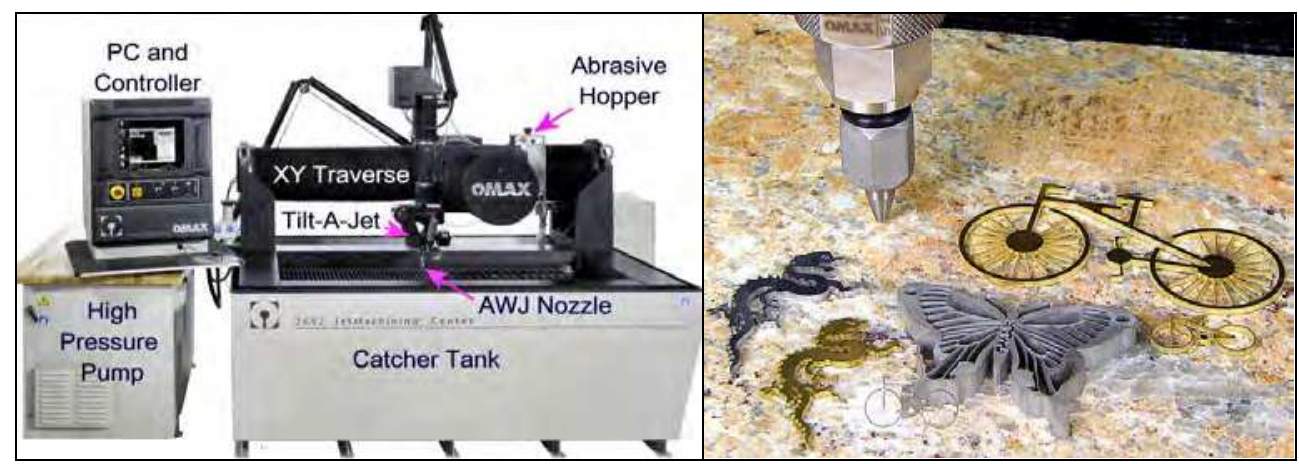

Fig. 1. Typical AWJ system and parts cut with AWJ nozzle (Liu \& McNiel, 2010)

The basic erosion mode of waterjets is consistent with micromachining processes. ${ }^{4}$ Waterjet machining is accomplished by erosion due to individual high-speed water droplets in a water-only jet or abrasives in an AWJ or ASJ impinging onto a workpiece. The size of machined features, such as the diameter of a hole or the kerf width of a slot, is proportional to the diameter of the jet stream in which the water droplets or abrasives are confined (Liu, 2010). Therefore, the key for developing micro abrasive-waterjet ( $\mu \mathrm{AWJ})$ technology is to reduce the diameter of the jet stream for meso-micro machining. Although the feasibility of applying waterjet technology for micromachining has been demonstrated in the mid-1990's, only limited progress has been made since then. The smallest features machined with commercial AWJs are generally larger than $200 \mu \mathrm{m}$. Several issues, such as the change in AWJ flow characteristics, poor flowability and clumping of fine abrasives, and nozzle clogging due to the wetting of abrasives caused by backsplash, have presented challenges for further downsizing AWJ nozzles. For example, micro WJs and low-pressure ASJs have been limited to machining relatively soft materials and to the singulation of SD chips for cellular phones, respectively (Jiang et al., 2005). AWJs have been predominantly used for machining applications.

Realizing the inherent advantages of AWJs and their potential for micromachining, considerable effort has been devoted to studying and seeking solutions to the above issues since the mid-2000's. Investigations have concentrated on understanding the physics of the supersonic/subsonic three-phase microfluidics of the abrasive slurry moving through smalldiameter mixing tubes and on issues related to the flow characteristics of fine particles. 5 These efforts have led to the development of novel approaches to resolving issues pertinent to AWJ micromachining. R\&D efforts have developed miniature AWJ nozzles and ancillary

\footnotetext{
${ }^{4}$ Strictly speaking, micromachining is defined as machined features in the micron size range. Machined features around $100 \mu \mathrm{m}$ are often referred to as meso-scale. In practice, however, features with sizes smaller than $150 \mu \mathrm{m}$ are often loosely referred to as micro-scale. With that understanding, we chose the practical and rather loose definition of meso- and micro-scale for features between $100 \mu \mathrm{m}$ and $250 \mu \mathrm{m}$ and less than and equal to $100 \mu \mathrm{m}$, respectively.

${ }^{5}$ Supported by OMAX's R\&D funds and NSF SBIR Grants \#0944229 (Phase I) and \#1058278 (Phase II).
} 
devices to machine features $100 \mu \mathrm{m}$ and smaller. These AWJs have been used to machine miniature parts made from a wide range of materials. As a result, the technical feasibility of further downsizing AWJ nozzles has been demonstrated. This article reviews the current status of $\mu \mathrm{AWJ}$ technology developments.

\section{Waterjet technology}

As discussed above, waterjet technology generally refers to the use one of any one of three types of jets: a water-only jet (WJ), an abrasive-waterjet (AWJ), and an abrasive slurry or suspension jet (ASJ). A waterjet is generated by pumping high-pressure water through an orifice to achieve supersonic speeds based on Bernoulli's principle. The water is pressurized to $400 \mathrm{MPa}$ and higher on the basis of Pascal's law of hydraulics. Although the basic features of modern waterjet technology were patented in 1939 by Leslie Tirrell (U. S. Patent No. $2,200,587)$, the lack of a water pump capable of producing the pressures needed for effective cutting limited the applications to surface cleaning and blasting.

Commercially viable 400-MPa pumping systems that took advantage of modern materials and design techniques were not introduced until the late 1970's. These high-pressure WJs, however, were limited to cutting only soft materials. In most cases, the waterjet-cut edges were often frayed with marginal edge quality at best. Abrasive-waterjets entraining abrasives into the WJ stream were developed by several independent R\&D teams. ${ }^{6,7}$ Abrasive-waterjets were subsequently commercialized in the mid-1980's. For the rest of the 1980 's, in the absence of precision control software and hardware, AWJs were mainly used for the rough cutting of materials, particularly those that were difficult to cut using established tools. Since then, much of the research and development has focused on characterizing the emerging technology and realizing its technological and manufacturing merits, as described in Section 1. It was soon realized that, with further advances toward automation, precision, and ease of use, AWJ cutting could have a large market potential in many industrial applications.

Advances in personal computers and peripherals, pumping technology, and materials sciences have greatly benefited the advancement of waterjet technology. In the early 1990's, PC-based CAD/CAM software and controllers were developed and optimized to drive AWJ systems, leading to significant cost reductions for automation while improving the userfriendliness of AWJ machining. The patented "compute first - move later" control algorithm revolutionized AWJ machining (Olsen, 1995). Based on a cutting model (e.g., Zeng \& Kim, 1995) and a set of parameters (including nozzle size and pressure; abrasive type, size, and flow rate; material type; path geometry; part thickness; and edge quality), the algorithm calculates the traverse speed of the nozzle along the entire cutting path derived from the CAD drawing of a part. Such a "smart" system greatly reduces the amount of operator input needed to optimize the cutting of a given geometry out of various materials. The path-linebased CAD program is then converted into an executable CAM module (Olsen, 1996). The entire part is machined simply by clicking a "Start" button on the display window without further intervention by the operator.

${ }^{6}$ As a team member of one of such R\&D group, the senior author developed a tube catcher to dissipate and terminate the residual erosive power of spent abrasives.

${ }^{7}$ Since Tirrell's 1939 patent, several AWJ patents have been issued (refer to U. S. Patent No. 4,555,872). 
One of the major improvements in recent years is the development of direct-drive pumps to replace the inefficient and bulky intensifier, resulting in increased efficiency from about $70 \%$ to about $90 \%$ along with reduced noise and pressure ripples. The simplicity of direct-drive pumps not only reduces operating and maintenance costs but also simplifies maintenance procedures. The availability of advanced materials together with design optimization has continuously extended the operating lives of pump components. Nowadays, the time between rebuilds for an advanced direct-drive pump has been extended to 1000 hours. ${ }^{8}$

Waterjets are generally amenable to 3D machining, although they have some limitations. Spent abrasives still possess considerable residual erosive power and could cause damage to the rest of the workpiece being cut, particularly if the waste stream comes in contact with other parts of the workpiece. For 3D parts with complex geometries, materials downstream and along the path of the cutting AWJ must be protected by a "catcher" to capture the spent abrasives, or by sacrificial pieces to absorb or dissipate the residual erosion power of the spent abrasives. For complex 3D parts, however, there is usually not enough room to place the catcher or sacrificial pieces where they are needed. Most commercial AWJ systems machine 2D and 2D+ parts, although there are commercial 5+-axis AWJ systems available for machining simple 3D parts. Alternatively, novel accessories for 2D AWJ systems have been developed that take into account the jet's geometry and imperfections in the raw materials to improve cutting accuracy, facilitating the fabrication of nearly 3D parts and multimode machining. Brief descriptions of representative accessories and their uses are given in subsequent sections.

\subsection{Fundamentals}

The PC-based CAD/CAM modules that incorporate a patented controller have been specifically designed to emphasize user friendliness. As a result, the underlying complex physical processes of AWJ flow phenomena are practically transparent to the operators. In this subsection, the fundamentals of AWJ flow phenomena are briefly described.

First, an AWJ is a supersonic, three-phase flow that involves fluid-fluid (air and water), fluid-solid (air, water, and abrasives), and solid-solid (abrasives and materials) interactions. During piercing and cutting, the complex flow is confined in a small space with rapidly changing boundary conditions. In addition, because water is slightly compressible, with a compressibility of approximately $15 \%$ at $400 \mathrm{MPa}$, numerical simulations of such complex flow phenomena have met with little success. CFD models have primarily been used for proof of concept (Liu et al., 1998). Fortunately, a majority of the research work was conducted in laboratory experiments at full scale.

The hydraulic power, $P$, required to generate a high-speed waterjet through an orifice is proportional to the product of the pressure, $p$, and the flow rate, $Q$, or

$$
P=p \times Q / c
$$

where $c$ is a constant that is equal to 60 when $P$ is in $\mathrm{kW}, p$ is in $\mathrm{MPa}$, and $Q$ is in $1 / \mathrm{min}$, for example. The flow rate can then be estimated based on the Bernoulli principle that the water flow rate through an orifice with a cross-sectional area $A$ is

$$
Q=c_{d} A \sqrt{2 p / \rho}
$$

\footnotetext{
${ }^{8}$ http:/ / www.omax.com/enduromax.php (8 August 2011).
} 
where $A=\pi d^{2} / 4, d$ is the orifice diameter, $c_{d}$ is the discharge coefficient with a typical value of $0.65, p$ is the pressure, and $\rho$ is the water density.

A normal diagram relating $P, Q, \mathrm{~d}$, and $p$ as derived from Eqs. (1) and (2) with $c_{d}=0.65$ is shown in Fig. 2 for a variety of orifice diameters. Knowing any two of the four variables enables determination of the other two. For example, if a cutting pressure of $4000 \mathrm{bar}$ is required using a $0.13 \mathrm{~mm}$ orifice, it will draw a flow rate of $0.43 \mathrm{l} / \mathrm{min}$ and the stream power will be $1.9 \mathrm{~kW}$ (dash-dotted lines). A motor larger than $1.9 \mathrm{~kW}$ must be used due to pump inefficiencies.

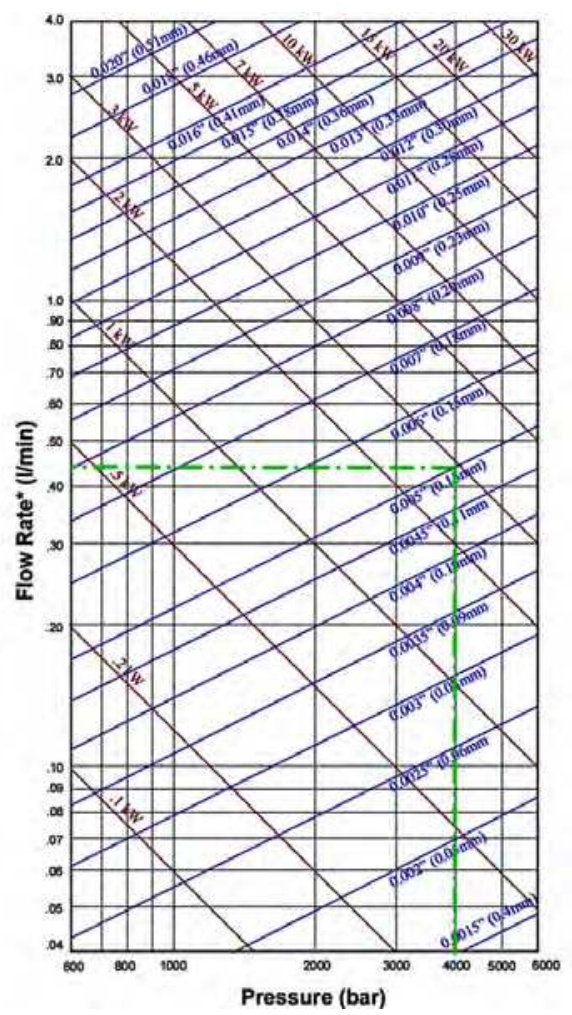

Fig. 2. Normal diagram of power, flow rate, and pressure

\subsection{Key components}

Abrasive-waterjet systems include both hardware and software components. They are integrated to maximize the cutting speed, user friendliness, and cost effectiveness.

\subsubsection{Hardware}

A typical AWJ system includes an AWJ nozzle, an abrasive feeding hopper, an X-Y traverse, a high-pressure pump, a motor, a PC, a catcher, and a support tank. Figure 1 illustrates an example of an AWJ system with several key components identified. Depending on the application, the catcher tank that also serves as the support for the $\mathrm{X}-\mathrm{Y}$ traverse, which 
usually has a cutting area ranging from about $0.7 \mathrm{~m} \times 0.7 \mathrm{~m}$ up to $14 \mathrm{~m} \times 3 \mathrm{~m}$ or larger. The $\mathrm{X}-\mathrm{Y}$ traverse, on which the AWJ nozzle, abrasive hopper, and other accessories may be mounted, has a position accuracy typically from $0.1 \mathrm{~mm}$ to $0.03 \mathrm{~mm}$ or better.

A high-speed waterjet is formed by using a high-pressure pump, either a hydraulic intensifier or a direct-drive pump, as illustrated in Fig. 3. Early high-pressure cutting systems used hydraulic intensifiers exclusively. At the time, the intensifier was the only pump capable of reliably creating pressures high enough for waterjet machining. A large motor drives a hydraulic pump (typically oil based) that in turn operates the intensifier. Inside the intensifier, hydraulic fluid pumped to about $21 \mathrm{MPa}$ acts on a piston through a series of interconnecting hoses and piping and a bank of complex control valves. The piston pushes a plunger, with an area ratio of 20:1, to pressurize the water to $420 \mathrm{MPa}$. The intensifier typically uses a double-acting cylinder. The back-and-forth action of the intensifier piston produces a pulsating flow of water at a very high pressure. To help make the water flow more uniformly (thus resulting in a smoother cut), the intensifier pump is typically equipped with an "attenuator" cylinder, which acts as a high-pressure surge vessel. The direct-drive pump is based on the use of a mechanical crankshaft to move any number of individual pistons or plungers back and forth in a cylinder. Check valves in each cylinder allow water to enter the cylinder as the plunger retracts and then exit the cylinder into the outlet manifold as the plunger advances into the cylinder. Direct-drive pumps are inherently more efficient than intensifiers because they do not require a power-robbing hydraulic system. In addition, direct-drive pumps with three or more cylinders can be designed to provide a very uniform pressure output without the use of an attenuator system. Improvements in seal design and materials combined with the wide availability and reduced cost of ceramic valve components now make it possible to operate a crankshaft pump in the 280 to $414 \mathrm{MPa}$ range with excellent reliability. This represents a major breakthrough in the use of such pumps for AWJ cutting. Nowadays, an increasing number of AWJ systems are being sold with the more efficient, quieter, and more easily maintained crankshaft-type pumps.

Abrasive-waterjet systems operating at $600 \mathrm{MPa}$ using intensifier pumps were introduced in the mid-2000's based on the notion that increased pressure means faster cutting. However, such a notion ignores several factors and issues. Specifically, any increase in pressure, for a given pump power, must be matched by a decrease in the volume flow rate, which leads to a decrease in the entrainment and acceleration of abrasives (Fig. 2). In an AWJ cutting system, water is used to accelerate the abrasive particles that perform the cutting operation. It has been shown that the kinetic power of the particles and thus the cutting power of the system is proportional to the hydraulic power of the waterjet. An increase in pressure at the same abrasive load ratio therefore does not yield any gain in cutting performance. Furthermore, high pressure is the enemy of all system plumbing due to material fatigue. As the pressure increases from 400 to $600 \mathrm{MPa}$, material fatigue significantly reduces the operating lives of components such as high-pressure tubing, seals, and nozzles, leading to considerably higher operating and maintenance costs (Trieb, 2010). ${ }^{9}$ Finally, an intensifier pump is $28 \%$ less efficient than a direct-drive pump. When the above factors are taken into

\footnotetext{
${ }_{9}^{9}$ For example, the maximum von Misses stresses in traditional 3:1 (outside diameter to inside diameter) ratio components will be about $800 \mathrm{MPa}$ to $1200 \mathrm{MPa}$, respectively. Based on data published in a NASA Technical Note (Smith et al., 1967), for hardened 304 stainless steel, the mean fatigue life will reduce from 35,000 cycles to 5,500 cycles, or a 6.4-fold reduction. As a result, high-pressure components are expected to reduce its life from several years to several months.
} 
consideration, the hydraulic power, rather than the pressure, is the main factor for cutting performance. Real-world experience has consistently demonstrated that the direct-drive 400MPa pump outperforms the 600-MPa intensifier pump in material cutting tests and in actual operations under the same electrical power (Henning et al., 2011a).

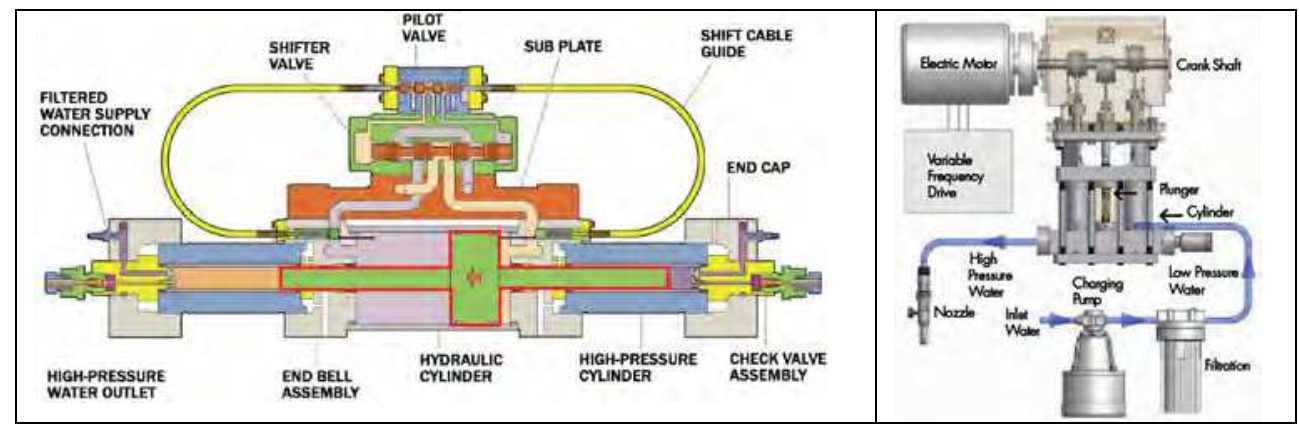

Fig. 3. Two types of high-pressure pumping mechanisms: an intensifier pump (left) and a complete direct-drive pump system (right) (Liu et al., 2010b)

Unlike a rigid cutting tool where material removal is carried out at the contact surface of a fixed-dimension tool and the workpiece, the AWJ is a flexible stream that diverges with the distance travelled. Consequently, AWJ machining has anomalies that must be compensated for with dedicated hardware components together with software control. For example, AWJ-cut edges are tapered depending on the speed of cutting. On the other hand, the spent abrasives still possess considerable erosive power to remove material along their paths. As a result, a catcher or sacrificial pieces must be used to capture spent abrasives or to prevent them from causing collateral damage to the rest of the workpiece. Therefore, AWJs would not be applicable to machine certain complex 3D parts when the placement of the catcher or sacrificial piece to protect the workpiece exposed to spent abrasives becomes impractical or impossible unless controlled depth milling or etching is used to machine blind features. To broaden the performance of AWJ machining in terms of precision and 3D machining, a host of accessories have been developed. Representative accessories include:

- A Tilt-A-Jet ${ }^{\circledR}$ dynamically tilts the nozzle up to 9 degrees from its vertical position. ${ }^{10}$ It removes the taper from the part while leaving the taper in the scraps.

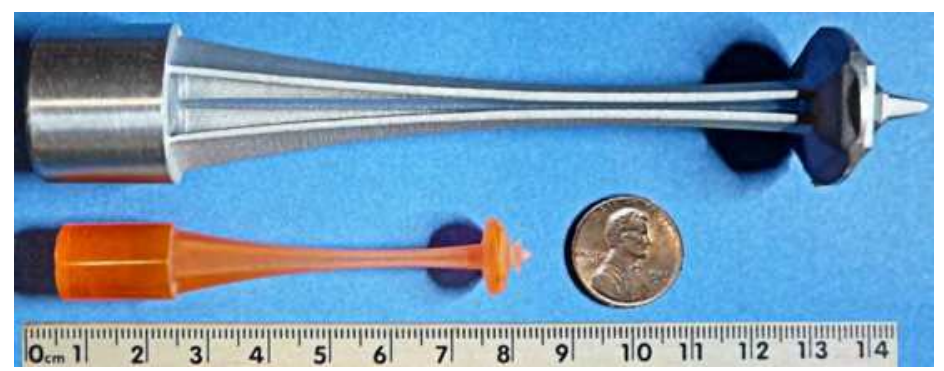

Fig. 4. Space Needle model machined with Rotary Axis (Liu \& McNiel, 2010)

${ }^{10}$ http:/ / www.omax.com/waterjet-cutting-accessories/Tilt-A-Jet/61 (8 August 2011) 
- A Rotary Axis or indexer rotates a part (Fig. 4) during AWJ machining around what is commonly referred to as the $4^{\text {th }}$ axis. ${ }^{11}$ It not only facilitates axisymmetric parts to be machined with AWJs but also enables multimode machining, including turning, facing, parting, drilling, milling, grooving, etching, and roughing.

- An A-Jet ${ }^{\mathrm{TM}}$, or articulated jet, tilts the nozzle up to 60 degrees from its vertical position. ${ }^{12}$ It is capable of beveling, countersinking, and 3D machining.

- A Collision Sensing Terrain Follower measures and adjusts the standoff between the nozzle tip and the workpiece to ensure that an accurate cut is maintained. Warped or randomly curved surfaces can be cut without the need to program in 3D. The collision sensing feature also protects components from becoming damaged if an obstruction is encountered during cutting.

By combining the Rotary Axis and the A-Jet, complex 3D features can readily be machined.

\subsubsection{Forms of waterjets}

Waterjets generally take one of three forms: a water-only jet (WJ), an abrasive-waterjet (AWJ), or an abrasive slurry or suspension jets (ASJ). Figure 5 shows drawings of these three jets. On the left is the WJ or the ASJ, depending upon whether the incoming fluid being forced through the small ID orifice is high-pressure water or abrasive slurry. On the right is the AWJ with gravity-fed abrasives entrained into the jet via the Venturi or jet pump effect. The abrasives are accelerated by the high-speed waterjet through the mixing tube.

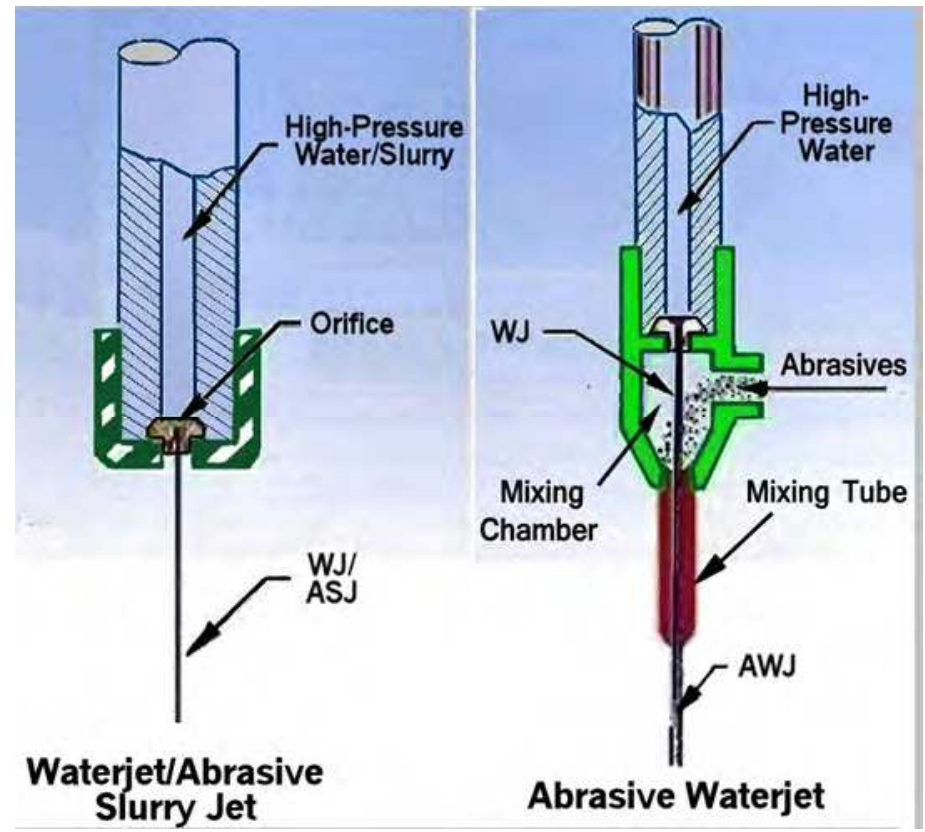

Fig. 5. Three forms of waterjets (Liu, 2009)

11 http:/ / www.omax.com/accessories-rotary-axis.php (8 August 2011)

12 http:/ / www.omax.com/waterjet-cutting-accessories/A-Jet/163 (8 August 2011) 
For R\&D and industrial applications, the majority of waterjet systems are AWJs. Water-only jets find only limited applications in the cutting of very soft materials. In principle, two-phase ASJs have a finer stream diameter, higher abrasive mass flow rate, and faster abrasive speed than do AWJs. As a result, the cutting power of ASJs is potentially up to 5 times greater than that of AWJs at the same operating pressure. Considerable R\&D effort has been invested in developing ASJs. However, the high-pressure components, such as orifices, check valves, and seals, through which the high-speed abrasive slurry flows are subject to extremely high wear. The absence of affordable materials with high wear resistance has limited ASJs to pressures around 70 to $140 \mathrm{MPa}$ for industrial applications (Jiang et al., 2005).

\subsubsection{Abrasives}

The most commonly used abrasive is garnet because of its optimum performance of cutting power versus cost and its lack of toxicity. It is also a good compromise between cutting power and wear on carbide mixing tubes. There are two types of garnet that are generally used: $\mathrm{HPX}{ }^{\circledR}$ and $\mathrm{HPA}^{\circledR}$, which are produced from crystalline and alluvial deposits, respectively. ${ }^{13}$ HPX garnet grains have a unique structure that causes them to fracture along crystal cleavage lines, producing very sharp edges that enable HPX to outperform its alluvial counterpart. There are other abrasives that are more or less aggressive than garnet.

\subsubsection{Speed of water droplets and abrasives}

When machining metals, glasses, and ceramics with AWJs, the material is primarily removed by the abrasives, which acquire high speeds through momentum transfer from the ultrahigh-speed waterjet. Therefore, knowing the speed of the abrasives in AWJs is essential for the performance optimization of AWJs. Several methods, such as laser Doppler anemometers or LDVs, laser transit anemometers or LTAs, dual rotating discs, and others, have been used to measure the speed of the waterjet and/or the abrasive particles to understand the mechanism of momentum transfer in the mixing tube in which the abrasives accelerate (Chen \& Geskin, 1990; Roth et al., 2005; Stevenson \& Hutchings, 1995; Swanson et al., 1987; Isobe et al., 1988). There is a large spread in the test results mainly due to the difficulty in distinguishing the speeds of the water droplets and of the abrasive particles using optical methods.

A dual-disc anemometer (DDA), based on the time-of-flight principle, was found to be most suitable for measuring the water-droplet and/or abrasive speed (Liu et al., 1999). Data discs made of Lexan and aluminum were successfully used to measure water-droplet speeds in WJs and abrasive particle speeds in AWJs. This was achieved by taking advantage of the large differences in the threshold speeds of water droplets and abrasive particles in eroding the two materials.

Figure 6 illustrates typical measurements of water-droplet speeds generated with an AWJ nozzle operating at several pressures from 207 to $345 \mathrm{MPa}$ in the absence of abrasives. The solid curve and the solid circles correspond to the Bernoulli speed, $V_{B}$, and the DDA measurements, $V_{w}$, with the abrasive feed port of the nozzle closed (i.e., no air entrainment), respectively. The Bernoulli speed is derived from Eq. (2). The close agreement between the two indicates that the WJ moves through the mixing tube with little touching of the

${ }^{13}$ http://www.barton.com/static.asp?htmltemplate=waterjet_abrasives.html (8 August 2011) 
sidewall. The open circles and dashed curve represent the abrasive speed, $V_{w a}$, with the feed port open and the corresponding best-fit values.

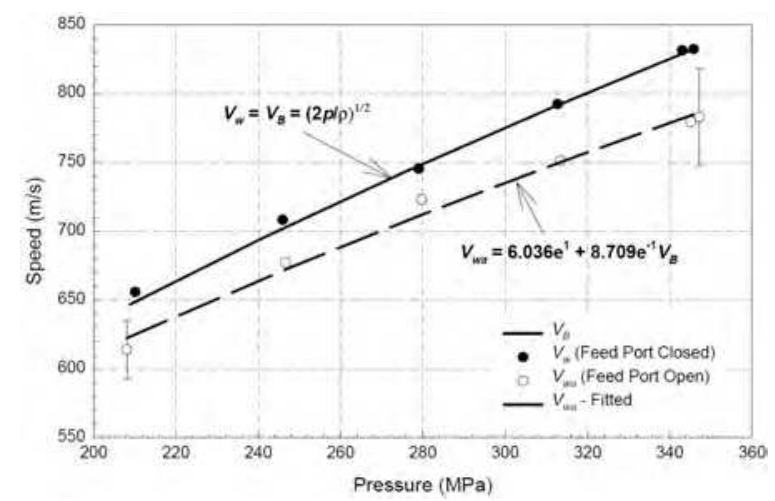

Fig. 6. Water-droplet speed in WJs exiting AWJ nozzle (Liu et al., 1999)

Measurements of abrasive speeds by entraining Barton 220-mesh garnet into the WJ are illustrated in Fig. 7. The measured and best-fit minimum, maximum, and average abrasive speeds are derived for a range of abrasive mass concentrations $C_{a}=0$ to $1.08 \% .14$ The average abrasive speed at $C_{a}=0.4 \%$ is $300 \mathrm{~m} / \mathrm{s}$, about $61 \%$ of the water-droplet speed. The decreasing trend in abrasive speed with $C_{a}$ is evident. The DDA has subsequently been applied to characterize the performance of AWJs (Henning et al., 2011a; Henning et al., 2011b).

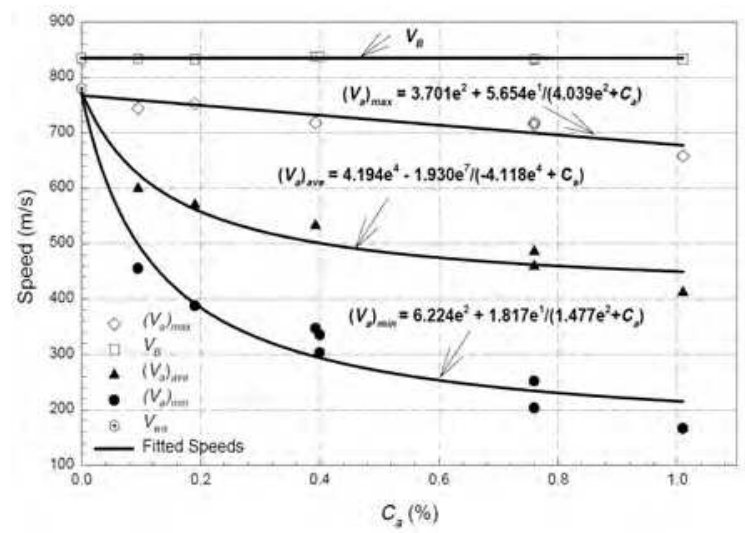

Fig. 7. Abrasive speed in AWJs, $p=345 \mathrm{MPa}$ (Liu et al., 1999)

\subsubsection{Control system}

Historically, AWJ cutting systems have used traditional CNC control systems employing the familiar machine tool "G-code." G-code controllers were developed to move a rigid cutting

${ }^{14} C_{a}$ is defined as the percentage ratio of the abrasive master flow rate in pounds per minute to that of the water flow rate in gallons per minute. 
tool, such as an end mill or mechanical cutter. The feed rate for these tools is generally held constant or varied only in discrete increments for corners and curves. Each time a change in the feed rate is desired, a programming entry must be made.

The AWJ definitely is not a rigid cutting tool; using a constant feed rate will result in severe undercutting or taper on corners and around curves. Moreover, making discrete step changes in the feed rate will also result in an uneven cut where the transition occurs. Changes in the feed rate for corners and curves must be made smoothly and gradually, with the rate of change determined by the type of material being cut, the thickness, the part geometry, and a host of nozzle parameters.

A patented control algorithm "compute first - move later" was developed to compute exactly how the feed rate should vary for a given geometry in a given material to make a precise part (Olsen, 1996). The algorithm actually determines desired variations in the feed rate in very small increments along the tool path to provide an extremely smooth feed rate profile and a very accurate part. Using G-code to convert this desired feed rate profile into actual control instructions for servomotors would require a tremendous amount of programming and controller memory. Instead, the power and memory of the modern PC is used to compute and store the entire tool path and feed rate profile and then directly drive the servomotors that control the $\mathrm{X}-\mathrm{Y}$ motion. This results in a more precise part that is considerably easier to create than if G-code programming were used.

The advent of personal computing has led to the development of PC-based "smart" software programs for controlling the operations of most modern AWJ systems and a host of accessories for speeding up the cutting while maximizing the precision and quality of cuts. The flexibility of PC programming incorporates the versatility of waterjet technology very well, and the integration of modern PC-based software and hardware takes full advantage of the technological and manufacturing merits of waterjet technology.

One of the advanced software packages used for AWJ machining is the PC-based CAD/CAM.15 It was particularly designed with "ease of use" in mind to allow operators to focus on the work at hand rather than the intricacies of the AWJ's behavior. The software has a built-in cutting model for common engineering materials that assigns each material a machinability index, as illustrated in Fig. 8. Another important input parameter is the edge or surface finish quality, which is defined in levels from Q1 to Q5, with Q1 representing rough cutting and Q5 representing the best edge quality. Figure 9 illustrates a "five-finger" part to demonstrate the five quality levels as a function of cutting speed. Note that the length of the finger is proportional to the cutting speed or the length of cut. The curvature and amplitude of the striation pattern, which is made of grooves caused by jet fluctuations, increases with increases in the cutting speed.16 The amplitude of the striation is also proportional to the abrasive size.

To compensate for the AWJ as a flexible abrasive stream, the control algorithm optimally adjusts the cutting speed along various segments of the tool path. As soon as the cutting begins, the nozzle moves slowly along the lead path such that the piercing is complete at the

\footnotetext{
${ }^{15}$ The description of the software package is based on OMAX's Intelli-MAX Software Suite. For detail, refer to (http://www.omax.com/waterjets/intelli-max-software-suite - (8 August 2011)

${ }^{16} \mathrm{http}: / /$ www.micromanufacturing.com/awj.htm (8 August 2011) or

http://oir.omax.com/media/OMAX_JetStream_Simulator.mp4 (8 August 2011)
} 
beginning of the tool path. The nozzle moves relatively fast along straight sections of the tool path and decelerates as corners are approached. Slowing down around corners ensures that there is minimal jet lag as the AWJ cuts the corner. Otherwise, there would be a

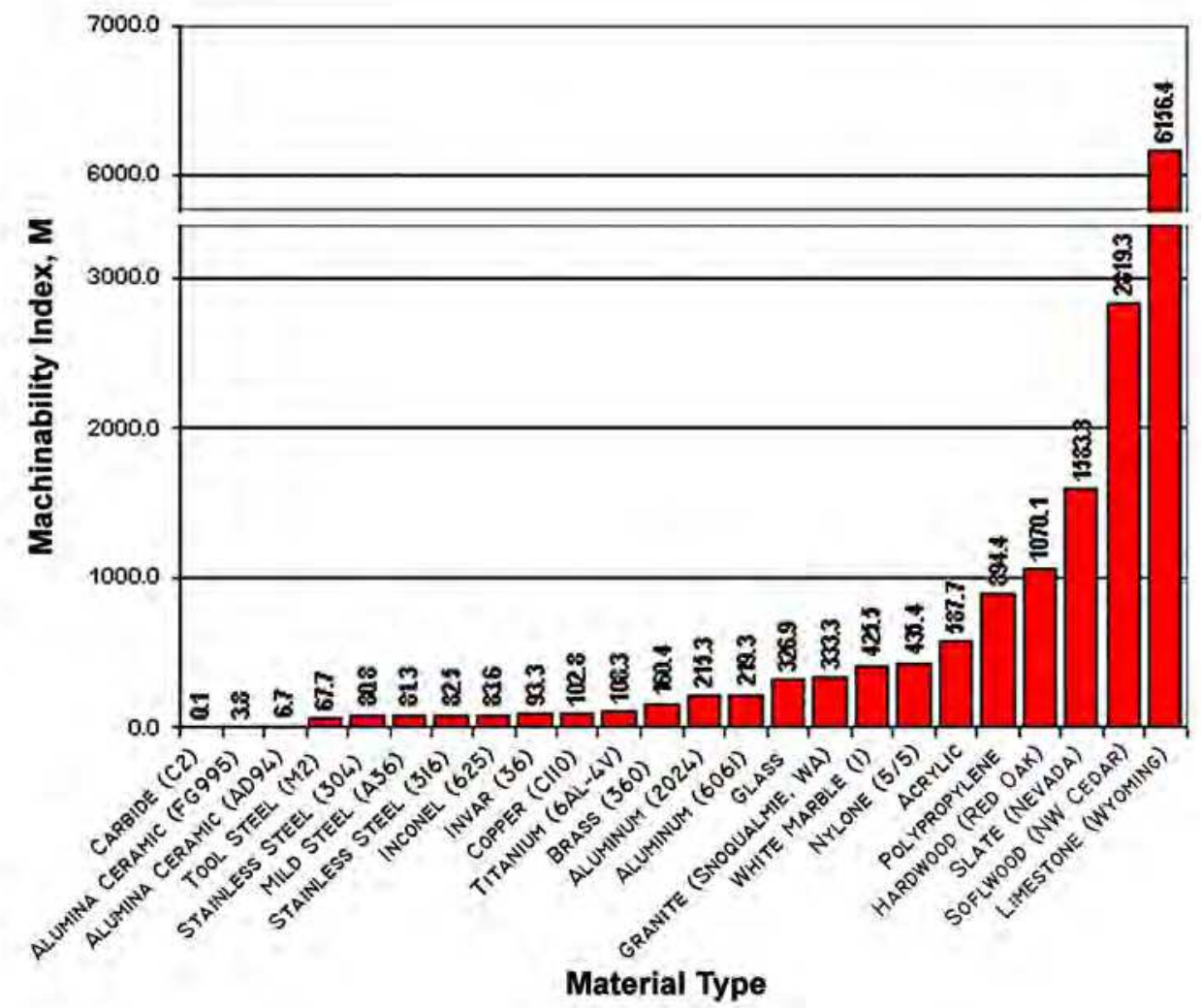

Fig. 8. Machinability of common engineering materials (Liu, 2009)

noticeable taper at the corner. The nozzle speeds up again after it passes the corner and accelerates to its maximum speed along straight segments. Figure 10 shows a color-coded diagram that illustrates the various cutting speeds used along a tool path.

The PC-based CAD is a built-in package that either works as a stand-alone program or allows drawings to be imported directly from other programs. It includes tools that are specific to AWJ machining such as automatic or manual lead in/out tools, tool path generation, collision prediction and correction, surface quality assignment tools, and many others. The PC-based CAM has many special features including the cutting model, six levels of cutting quality, taper compensation, estimate of time required to machine a part, report generation, creation and tracking of multiple home locations, rotating, scaling, flipping, and offsetting, among others. The CAM program also offers several special benefits such as part nesting, low-pressure piercing and cutting for brittle and delicate materials, the resizing of parts, and others. 


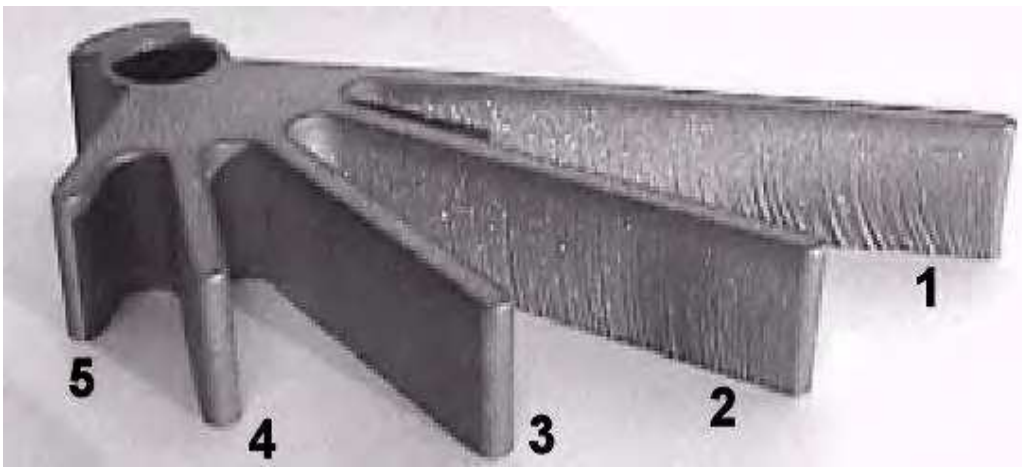

a) Fingers at qualities Q1 through Q5

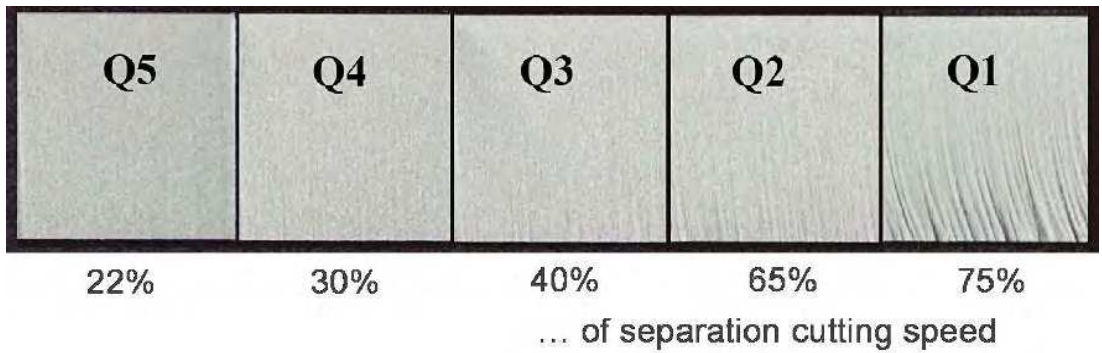

b) Striation patterns for Q1 through Q5

Fig. 9. AWJ-machined five-finger part (Liu et al., 2009)

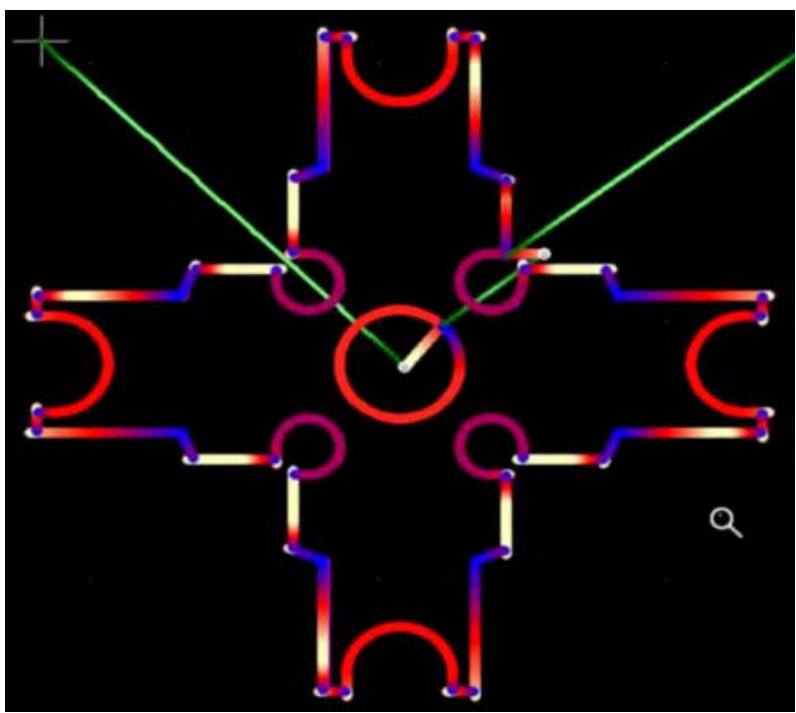

Fig. 10. Cutting speeds along tool path: white \& light - fast; blue \& dark - slow; green traverse line (Olsen, 2009) 


\subsection{Fatigue performance}

Current specifications require that AWJ-cut aluminum and titanium parts that will be used in fatigue-critical aerospace structures undergo subsequent processing to alleviate concerns of degradation in fatigue performance. It has been speculated that the striation patterns induced by AWJs (Fig. 9) could be a source of the initiation of micro-cracks under repeated loading. The requirement of a secondary process for AWJ-machined parts greatly negates the merits (cost effectiveness) of waterjet technology. An R\&D program was initiated to revisit the fatigue performance of AWJ-machined aircraft aluminum and titanium parts for fatigue-critical applications by incorporating the most recent advances in waterjet technology (Liu et al., 2009a). 17 "Dog-bone" specimens were prepared by using AWJ and CNC machining. Several "low-cost" secondary processes, including dry-grit blasting with 180-grit aluminum oxide and sanding, were applied to remove the visual appearance of the striation patterns on AWJ-machined edges in an attempt to improve fatigue life. Fatigue tests of dog-bone specimens were conducted in the Fatigue and Fracture laboratory at the Pacific Northwest National Laboratory (PNNL).

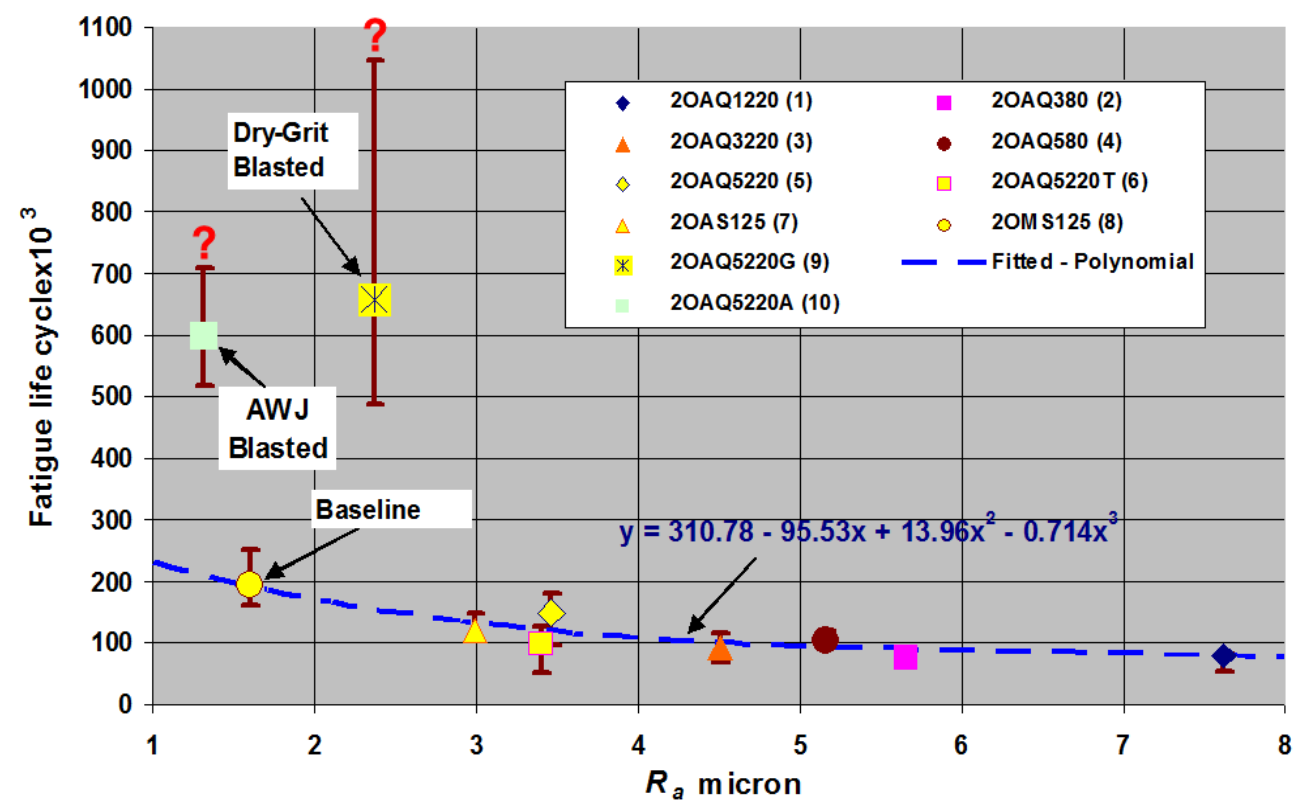

Fig. 11. Fatigue life versus $R_{a}$ of aircraft aluminum 2024 T3 (Liu et al., 2009b)

Figure 11 illustrates the results of fatigue tests for the aluminum dog-bone specimens. The abscissa and ordinate are the edge surface roughness, $R_{a}$, and the fatigue life, respectively. For the AWJ-cut specimens, $R_{a}$ was measured near the bottom of the edge where the amplitude of the striation is at the maximum. The "error bars" in the figure represent the maximum and minimum fatigue life values from the measurements. Except for the dry-grit

17 This work was a collaboration among OMAX Corporation, Boeing, Pacific Northwest National Laboratory (PNNL), and National Institute of Standards and Technology (NIST). 
and AWJ-blasted specimens, Fig. 11 shows that the fatigue life depends mainly on $R_{a}$ whether the dog-bone specimens were machined with AWJs (both as-cut samples and those with secondary sanding) or conventionally.

On the other hand, the grit-blasting process only reduces the $R_{a}$ from 3.4 to $2.3 \mu \mathrm{m}$, although most specimens did not break at the gage. The question marks (?) in the figure correspond to the number of test cycles at which the test was terminated, whether the specimen broke at the gage or not even though it was not necessarily a failure (at the gage). The "average" fatigue life for the specimens prepared with the combined process is at least 3 or 4 times longer, respectively, than that for specimens machined by a conventional tool or by AWJs (Liu et al., 2009b). Fatigue tests were also conducted on the aircraft titanium dog-bone specimens, and a similar trend of improvement in the fatigue performance was observed (Liu et al., 2011a).

Subsequent measurements at the x-ray diffraction facility of NIST's Center for Neutron Research have demonstrated that the dry-grit and AWJ blasting processes induce residual compressive stresses on the AWJ-machined edges (Liu et al., 2009b). The residual compressive stresses induced by dry-grit and AWJ blasting were responsible for the fatigue performance improvement. The ability to improve fatigue performance further would have a significant impact on many micromachined parts (e.g., orthopedic implants).

\section{3. $\mu$ AWJ technology}

Waterjet machining, a top-down manufacturing process, is accomplished by erosion as individual high-speed water droplets in a WJ or abrasive particles in an AWJ/ASJ impinge onto a workpiece. At the microscopic scale, this erosion process by individual water droplets or abrasive particles is consistent with a micromachining process, especially when the droplet or particle size is at micron and submicron scales. At the macroscopic scale, the size of a machined feature, such as the diameter of a hole or the kerf width of a slot, is proportional to the diameter of the jet stream in which the water droplets and abrasives are confined. Therefore, the waterjet stream diameter governs the size of machined features and must be downsized appropriately for meso-micro machining. Figure 12, modified from the drawing presented by Miller (2005), compares the stream diameters of various types of waterjets with the beam diameters of lasers. The solid and dotted portions of the lines signify the normal and outside ranges of stream/beam diameters, respectively. The outside range is either difficult or impractical to achieve for meso-micro machining.

Most of the advantages of waterjet technology discussed in Section 1 apply equally to AWJ meso-micro machining. Although the technical feasibility of applying waterjet technology for meso-micro machining has been demonstrated since the mid-1990's, $\mu \mathrm{AWJ}$ technology remains in the research and development stage (Miller et al., 1996). For cutting a limited set of soft materials, WJs using micron-size orifices have been applied reliably in production environments. In principle, the two-phase ASJs are more aggressive and inherently have smaller stream diameters than the three-phase AWJs. The lack of suitable engineering materials to fabricate highly wear-resistant check valves and other components exposed to the aggressive ASJ has limited its pressures to between about 70 and $140 \mathrm{MPa}$ (Jiang et al., 2005). Most ASJ systems adopt batch feeding of the slurry just upstream of the orifice in order to isolate the abrasives from the high-pressure pump. 


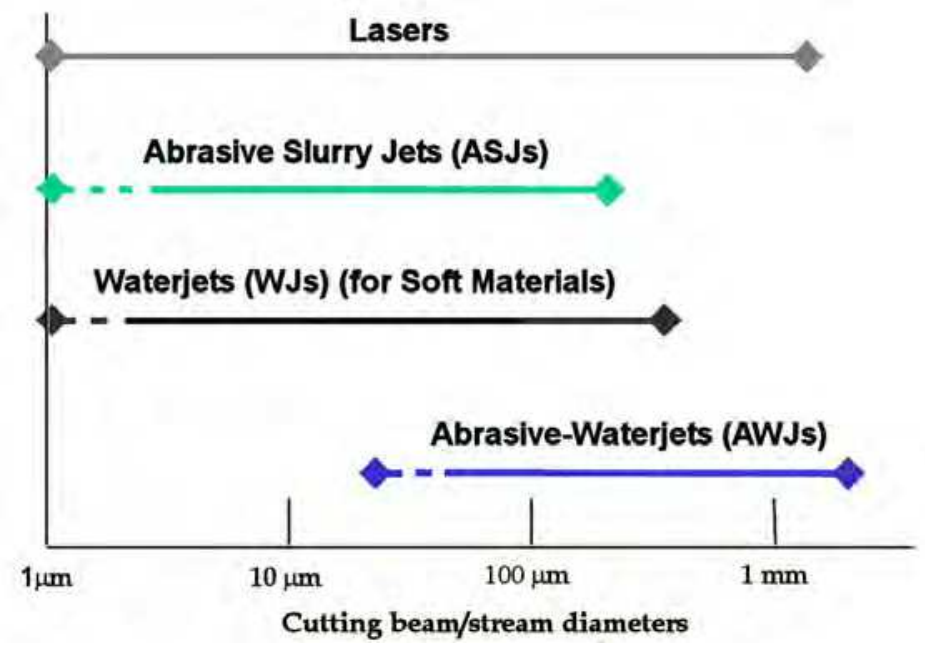

Fig. 12. Comparison of stream/beam diameters of waterjets and lasers (modified from Miller, 2005)

Abrasive-waterjets remain the mainstream of waterjet technology. Recent R\&D efforts in further downsizing of AWJ nozzles have shown good promise, as described in Section 1. Most of the issues associated with downsizing AWJ nozzles beyond the current state of the art have been identified. Novel processes have been and are still being developed to meet the challenges to resolving these issues.

\subsection{Challenges}

Nowadays, the smallest features that can be machined with miniature AWJs are around 200 to $300 \mu \mathrm{m}$. Further downsizing of the AWJ presents considerable challenges and difficulties. The supersonic, three-phase AWJ is one of the most complex flow phenomena, particularly because it also involves fluid-fluid, fluid-solid, and solid-solid interactions in a rapidly changing spatial environment. When the ID of the mixing tube is reduced to sizes at which surface tension becomes important, the abrasive slurry has transitioned into a microfluidic flow, leading to additional complexities. In parallel, the size of the abrasive particles must be reduced proportionally with the size of the mixing tube. There are several concerns regarding gravity feeding of fine abrasives, as the flowability of the abrasives deteriorates with particle size distribution. In addition, fine abrasives tend to coagulate or clump together, causing difficulties in achieving consistent and uniform feeding of abrasives to the $\mu \mathrm{AWJ}$ nozzle. Several issues associated with AWJ machining and meso-micro machining are briefly discussed below.

\subsubsection{Microfabrication of $\mu$ AWJ nozzle}

The $\mu \mathrm{AWJ}$ nozzle consists of three key components: the orifice, the mixing tube, and the nozzle body, in which the orifice and mixing tube are housed. The optimum ID ratio of the orifice and mixing tube is between 2 and 3 . The optimum aspect ratio of the mixing tube (bore length to ID) is about 100 for production AWJ nozzles, which allows adequate acceleration of the entrained abrasives by the high-speed water droplets to produce a focused AWJ stream with 
minimal spread at the nozzle exit. Downsizing of the orifice and nozzle body is within the current capability of micromachining technology, as orifices made of sapphire or diamond with IDs of $10 \mu \mathrm{m}$ and smaller are commercially available. At present, mixing tubes with IDs greater than $200 \mu \mathrm{m}$ are fabricated by wire EDM. The challenge is to fabricate mixing tubes with IDs less than $200 \mu \mathrm{m}$ and an adequate aspect ratio.

\subsubsection{Microfluidics}

As the mixing tube ID is decreased, the capillary effect becomes increasingly important together with the increase in the slurry flow resistance. A meniscus column of water supported by the capillary force will eventually fill the entire bore of the mixing tube. A backsplash of water and abrasives, produced by the front of the AWJ impacting the upper surface of the water column, could reach the interior surface of the nozzle body and the lower portion of the abrasive feed tube, leaving a layer of wet abrasives on these surfaces. After many on-off cycles, buildup of the wet abrasive layers on those surfaces would restrict and eventually block the dry abrasives flowing into the mixing tube. An insufficient quantity of abrasives adversely affects the cut quality. Therefore, optimum nozzle operations to maintain a desired cut quality require the mitigation of the accumulation of wet abrasives on all interior surfaces of the nozzle and the feed tube.

Remedies have been developed, with limited success, to minimize the degree of nozzle clogging by wet abrasives. One of the remedies is the use of vacuum assist and water flushing (Hashish, 2008). The incorporation of such a remedy into $\mu \mathrm{AWJ}$ nozzles is, however, not suitable due to the resultant increase in bulkiness and added complexity in process control.

\subsubsection{Feeding of fine abrasives}

As a rule of thumb, the optimum size distribution of abrasives for a given nozzle is such that the maximum abrasive size is no larger than one-third of the mixing tube ID to prevent clogging due to the bridging of two large abrasives. For example, for a mixing tube with a $100-\mu \mathrm{m}$ ID, the abrasive size must be less than about $30 \mu \mathrm{m}$. Although fine abrasive or powder flow is a complex phenomenon, because it is affected by so many variables, it is generally accepted that flowability under gravity feed increases with the particle size (Yu et al., 2011; Liu et al., 2008b). Flowability in this sense simply means the ability of a powder to flow. As the abrasives become finer and finer, they eventually cease to flow through the feed tube when being gravity fed. In addition, fine abrasives tend to coagulate or clump together by static electricity or humidity. Abrasives that clump together would have difficulty flowing from the hopper to the mixing tube. As a result, the abrasive flow is unsteady at best, which leads to inconsistent abrasive feeding or even flow stoppage. Inconsistent abrasive flow would result in deterioration of the cut quality.

\subsubsection{Design optimization of traverse systems}

For an AWJ system with a flexible jet stream, the quality of an AWJ-machined part depends on additional parameters inherent to the characteristics of a waterjet. Note that the jet spreads with the distance it travels. Therefore, the profile of the jet, the abrasive size distribution, the abrasive flow rate, and the uniformity of abrasive feed will all affect the machining precision and cut quality. For example, the kerf width of a slot and/or the 
minimum diameter of a circle are usually used to define the machining precision. The striation pattern and edge taper are often used as qualifiers for the cut quality. For mesomicro machining, special attention must be devoted to optimization of both the design of the $X-Y$ traverse and the characteristics of the $\mu \mathrm{AWJ}$. Nowadays, linear traverses can be built with nanometer resolution and position accuracy, but their costs increase exponentially with the resolution. In designing a $\mu \mathrm{AWJ}$ system, one must take into consideration the ultimate machining precision achievable with a $\mu \mathrm{AWJ}$ nozzle. Overdesigning the traverse system for AWJ meso-micro machining would have no real benefit and would only inflate the cost of goods.

\subsection{Novel solutions under development}

Under support from OMAX's R\&D funds and an NSF SBIR Phase I grant, a series of feasibility investigations were conducted regarding the development of $\mu \mathrm{AWJ}$ technology. The success of these investigations, together with the tremendous market potential of $\mu \mathrm{AWJ}$ technology, has led to the award of an NSF SBIR Phase II grant for the development of a $\mu \mathrm{AWJ}$ system prototype for meso-micro machining.

R\&D efforts to meet the challenges in developing the $\mu \mathrm{AWJ}$ technology and to resolve various issues associated with nozzle downsizing have led to the development of several novel approaches. Each of the issues described in Section 3.1 has been investigated carefully, and practical solutions have been proposed. Additional solutions are currently being sought.

- A better understanding of the relevant microfluidics has led to the development of novel processes to improve the flowability and uniform feeding of fine abrasives and, thus, mitigate nozzle clogging.

- Efforts are being made to reduce the tolerance stacking error.

- System optimization is being made to develop a prototype of an efficient and costeffective precision $\mu \mathrm{AWJ}$ machine.

- $\quad$ R\&D and beta miniature AWJ nozzles, with and without ancillary devices, have been developed for meso- and micro-scale test cutting.

Success in the above research efforts would facilitate further downsizing of AWJ nozzles with the goal of achieving the capability to machine features around 100 to $50 \mu \mathrm{m}$. Another benefit of nozzle downsizing is that multiple small nozzles can be supported by a single pump designed for large nozzles. For the beta nozzles, a multi-nozzle platform has been developed and tested for machining up to four identical parts simultaneously.

Test cuts were made using these nozzles and ancillary devices to fabricate samples from a broad range of engineering materials to demonstrate the versatility of waterjet technology for meso-micro machining. The designs, drawings, and materials of many test samples were furnished by industrial and academic collaborators and customers with specific applications in mind. The finished parts were subsequently returned to the providers for inspection and evaluation. Based on the results of these evaluations, the performance of $\mu \mathrm{AWJ}$ technology for various applications was assessed.

\section{AWJ-machined samples and features}

In this section, selected machined samples are presented and discussed to demonstrate the versatility of $\mu \mathrm{AWJ}$ technology for meso-micro machining. 


\subsection{Basic features}

The R\&D nozzles and ancillary devices discussed above were used to pierce holes and machine slots to demonstrate their ability to machine very small features. Emphasis was made to determine the smallest features that could be machined with these nozzles with and without ancillary devices and also without perfecting the piercing and machining processes. Figure 13 illustrates 3D micrographs of a small hole pierced in a thin stainless steel shim 100 $\mu \mathrm{m}$ thick. The hole was pierced with a $380-\mu \mathrm{m}$ nozzle and a proprietary ancillary device to reduce the effective diameter of the AWJ. ${ }^{18}$ The diameter of the hole on both the entry and exit sides is around $100 \mu \mathrm{m}$. As a rule of thumb, the size of AWJ-cut features is slightly larger than the stream diameter of the AWJ or the mixing tube. In other words, the smallest hole that can be pierced with the $380-\mu \mathrm{m}$ nozzle is approximately $400 \mu \mathrm{m}$. The ancillary device has effectively reduced the stream diameter of the AWJ by a factor of 4 . The advantage of using such a device is to enable relatively large AWJ nozzles and coarse abrasives to cut parts with features smaller than the diameter of the mixing tube. Note that Fig. 13 represents micrographs of the as-pierced hole. The circularity of the hole could be significantly improved by trepanning after piercing, which would increase the hole diameter slightly.

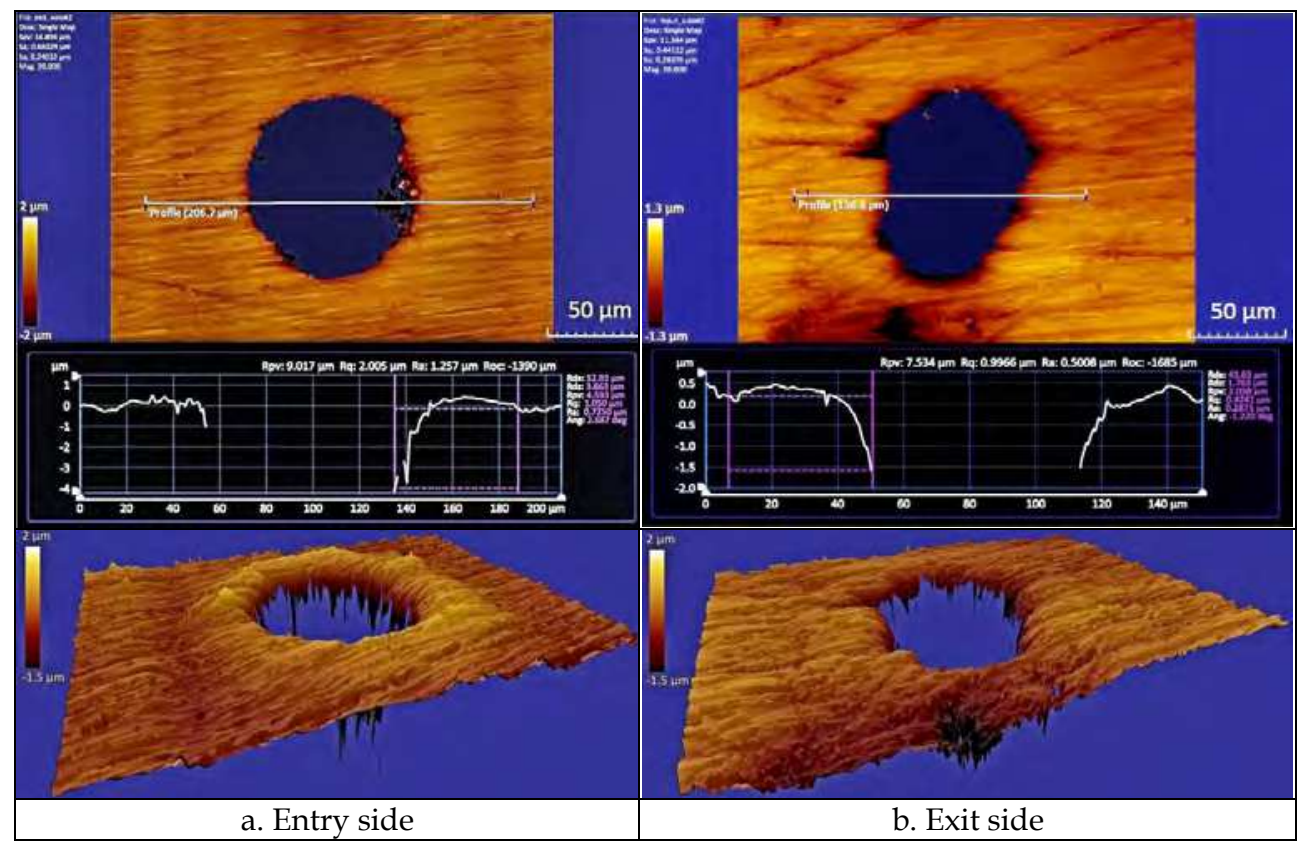

Fig. 13. Micrographs of holes pierced on 316 stainless steel shim - courtesy of Zygo Corp and Microproducts Breakthrough Institute (Liu et al., 2011b)

${ }^{18}$ The $380 \mathrm{~mm}$ nozzle is one of the production nozzles. The nozzle size refers to the mixing tube ID which is twice the orifice ID. 
Figure 14 illustrates three narrow slots machined in a stainless steel shim $0.25 \mathrm{~mm}$ thick. The kerf width of the slots was measured to be approximately $92 \mu \mathrm{m}$. These slots were machined with the $380-\mu \mathrm{m}$ nozzle together with another ancillary device to reduce the effective stream diameter of the nozzle. Note that the kerf width is smaller than the width of the fingerprints impressed on the surface of the shim. ${ }^{19}$

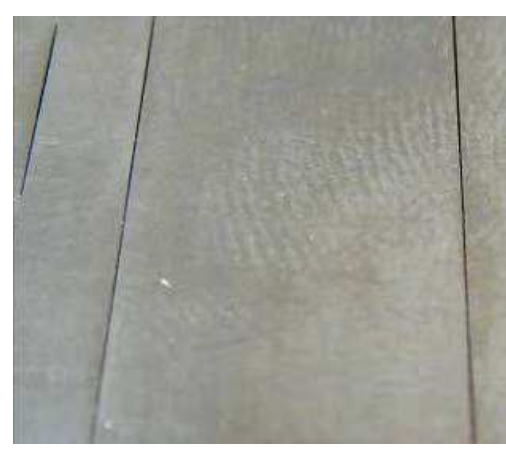

a. Three thin slots

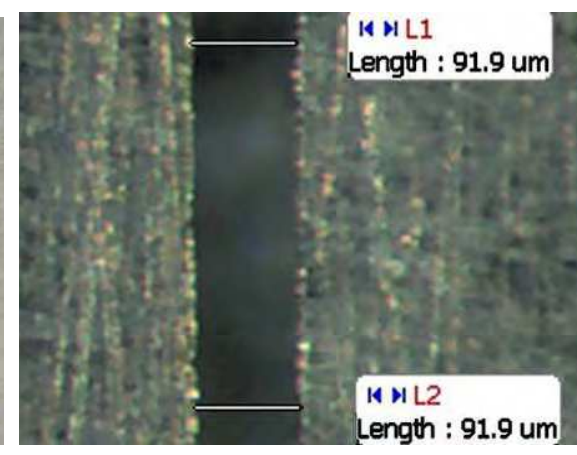

b. Micrograph of slot

Fig. 14. AWJ-machined slots using a novel ancillary device (Liu \& Schubert, 2010)

\subsection{Components for green energy products}

At the Precision Engineering Research Group (PERG) of MIT, a novel concept was conceived to improve the efficiency of small motors/generators by means of surfacemounted armatures. ${ }^{20}$ Conventional armatures composed of multiple turns of round wires have a low compaction factor (ratio of volume filled by conducting wires to total allotted conductor volume) because there are gaps among wires resulting in relatively high armature resistance and reduced performance. The concept considered replacing wirewound armatures with slotted copper tubes of appropriate annular dimensions (Trimble, 2011 - patent pending). The smaller the kerf width of the cuts, the higher the compaction factor and better the performance of the armature become. Researchers at PERG ran into problems in machining narrow slots on copper tubes. Due to the high reflectivity of copper, laser cutting splattered. On the other hand, the tube geometry prohibited the use of wire EDM, while sinking EDMs were too slow and costly.

Abrasive-waterjets were applied cost-effectively to machine large-aspect-ratio microchannels for fuel cells on stainless steel and titanium shims (Liu et al., 2008a). Certain AWJ-cut slot/rib patterns on some materials were fabricated that were otherwise too difficult and/or costly to be machined by conventional tools. By mounting the copper tube on a rotary indexing tool, a 254- $\mu$ m nozzle successfully machined 16 narrow slots on the copper tube, as illustrated in Fig. 15.21 Preliminary results demonstrated that $\mu$ AWJ technology could be an enabling tool for this method of surface armature manufacturing.

\footnotetext{
19 Since the kerf width of a slot rather than the separation between slots is limited by the stream diameter of the $\mu \mathrm{AWJ}$, the minimum scale of micromachining is therefore defined by the kerf width.

${ }^{20} \mathrm{http}: / /$ pergatory.mit.edu/ (8 August 2011)

${ }^{21}$ The $254-\mu \mathrm{m}$ nozzle is an $R \& D$ nozzle currently being beta tested.
} 


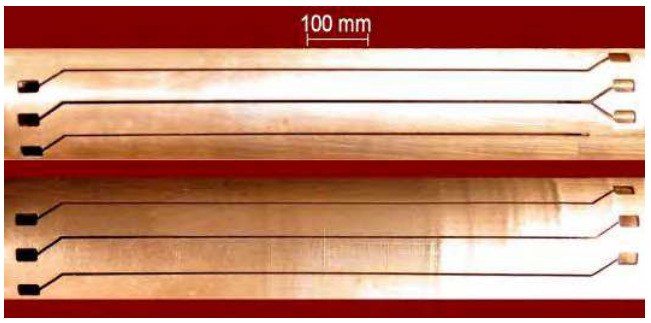

Fig. 15. AWJ-slotted copper tubes (design provided by MIT PERG) (Liu et al., 2011b)

\subsection{Biomedical components}

Advanced micromachining technology has been favorable for fabricating biomedical devices, which are continually becoming smaller and more intricate in terms of size, shape, and material. $\mu \mathrm{AWJ}$ technology shows great potential for such applications based on the market size and current trends, the urgent need for cost reductions in healthcare, and the nature of biomedical components. For example, mini- and micro-plates for orthopedic implants to repair/reconstruct bone and skull fractures are one of the strong candidates for $\mu \mathrm{AWJ}$ technology (Haerle et al., 2009). Titanium is often used for these plates because of its biocompatibility. While conventional machine tools have difficulty in machining titanium, AWJs cut titanium $34 \%$ faster than stainless steel at considerably lower costs (Fig. 8). Note that material toughness does not play an important role in AWJ cutting. Therefore, materials that would normally be cut in an annealed condition may be cut in a hardened condition with insignificant loss of productivity. For emergency operations, in particular, a part could be machined by an AWJ from design to finish in minutes. Another potential benefit is improvements in the fatigue performance of implants via dry-grit blasting (Section 2.3).

Figure 16 illustrates several samples of AWJ-machined mini- and micro-plates made of titanium and stainless steel. The mesh-type mini-plates are made from titanium shim stock $0.34 \mathrm{~mm}$ thick. These plates are commonly used in facial and skull repair and reconstruction (Haerle et al., 2009). Machining was carried out at a pressure of $380 \mathrm{MPa}$ with the use of the $254-\mu \mathrm{m}$ nozzle. The fine-mesh mini-plate (lower right in photo) took about 20 minutes to complete. Optimization of the nozzle performance is expected to reduce the machining time.

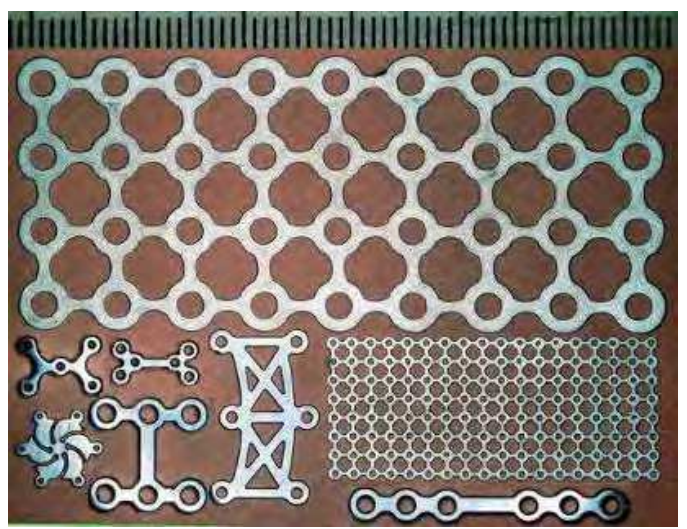

Fig. 16. Titanium and stainless steel orthopedic parts. Scale: $\mathrm{mm}$ (Liu et al., 2011b) 
The same 254- $\mu \mathrm{m}$ nozzle was also applied to cut a flexure to be used as a component of a medical device (Begg, 2011 - patent pending). The material was 6061 T3 aluminum with a thickness of $9.5 \mathrm{~mm}$. The key feature is a narrow bridge, with a target width of $0.25 \mathrm{~mm}$, between two connecting members of the flexure. Figure 17 shows a portion of an AWJ-cut flexure. The two lengths, L1 and L2, shown in the photo are the widths of one of the narrow bridges and one of the connecting members of the flexure. Note that the width of the bridge was measured at $0.31 \mathrm{~mm}$.

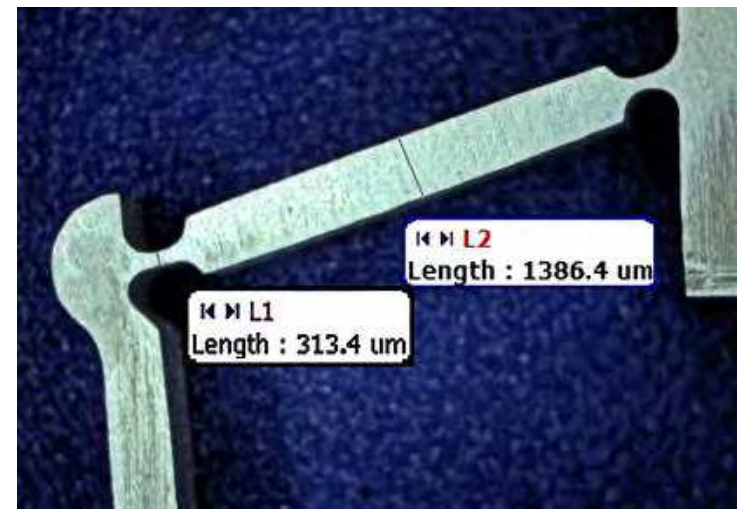

Fig. 17. Small aluminum flexure (MIT PERG) (Liu et al., 2011b)

\subsection{Planetary gear set}

For machining miniature mechanical components, the $254-\mu \mathrm{m}$ nozzle was used to cut a set of planetary gears. The set consists of seven gears [a sun gear $(9.68 \mathrm{~mm} \mathrm{OD})$, a ring gear (19.05 mm OD), and five small planetary gears (3.55 mm OD)], a gear mounting plate, and a gear carrier. Figure 18 illustrates the components of the gear set. Also included are the tool paths of the seven gears corresponding to the screen display of the PC-based CAD program

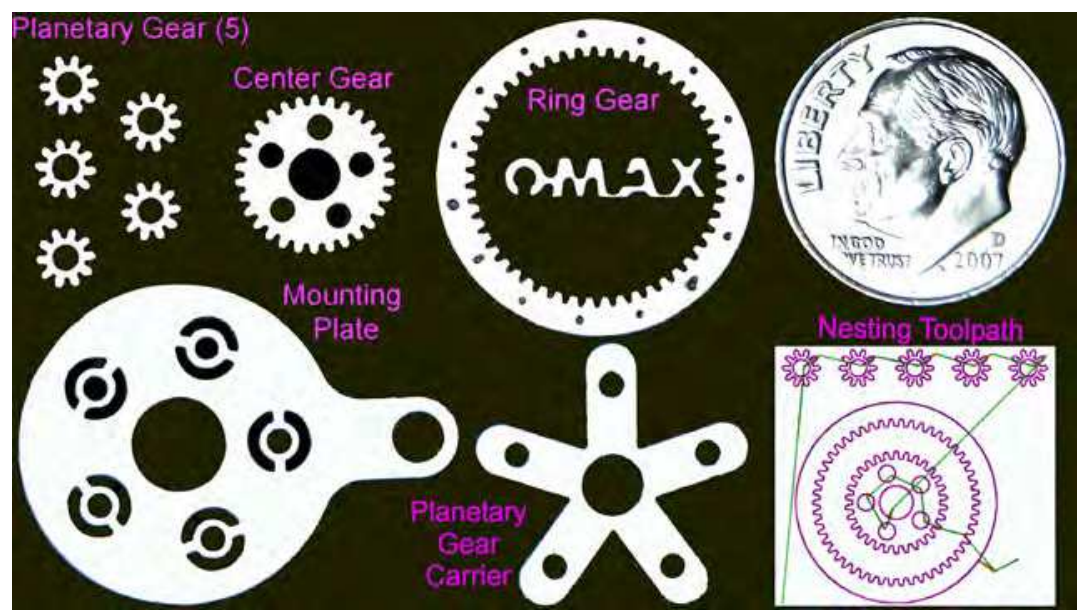

Fig. 18. Components and tool paths of planetary gear (Liu et al., 2011b) 
LAYOUT.22 Note that tool paths with a magenta color represent an edge quality of 3 out of 5 , with 5 as the best edge quality. The ring and sun gears were nested to save material. The LAYOUT diagram was then transferred to the CAM program MAKE to machine the planetary gear set from 0.62 -mm-thick stainless steel plate using the $254-\mu \mathrm{m}$ nozzle. ${ }^{23}$ Figure 19 illustrates the assembled planetary gear set driven by a micro spur gear head motor (Solarobotics, Model GM14a) powered by a single AAA battery.

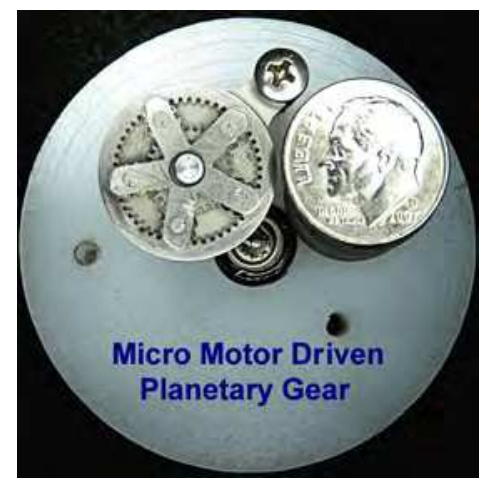

Fig. 19. Gear assembly (Liu et al., 2011b)

\subsection{Near 3D parts}

The $380-\mu \mathrm{m}$ nozzle was set up together with the Rotary Axis to machine axisymmetric features. ${ }^{6}$ The Space Needle models shown in Fig. 4 are examples cut with that setup. Subsequently, a titanium tube with an OD of $6 \mathrm{~mm}$ and an ID of $0.6 \mathrm{~mm}$ was mounted on the Rotary Axis. Interlocking features were machined on the titanium tube by the nozzle with the Rotary Axis rotating. A steel rod was inserted into the titanium tube serving as a sacrificial

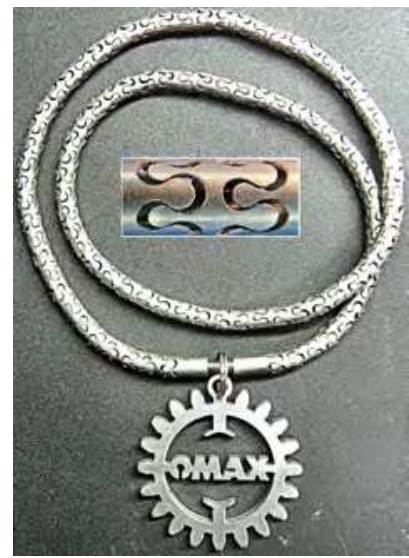

Fig. 20. Titanium interlocking link (Liu et al., 2011b)

22 http:/ / www.omax.com/waterjets/layout-software (8 August 2011)

${ }^{23} \mathrm{http}: / /$ www.omax.com/waterjets/make-software (8 August 2011) 
piece to protect the opposite wall of the tube from being damaged by the spent high-speed abrasives. Figure 20 illustrates a photograph of the interlocking link. Since there are no soldering joints on the tube, the link is quite strong as compared with similar ones that are welded together. Also shown in the figure is a magnified view of one of the individual links. Figure 21 illustrates an A-Jet-cut aluminum blisk $(\mathrm{OD}=25.5 \mathrm{~mm}$; thickness $=13.1 \mathrm{~mm})$. With the combination of the $380-\mu \mathrm{m}$ nozzle and the A-Jet capable of tilting the AWJ up to \pm 60 degrees from the vertical, many complex $3 \mathrm{D}$ features can be readily machined.

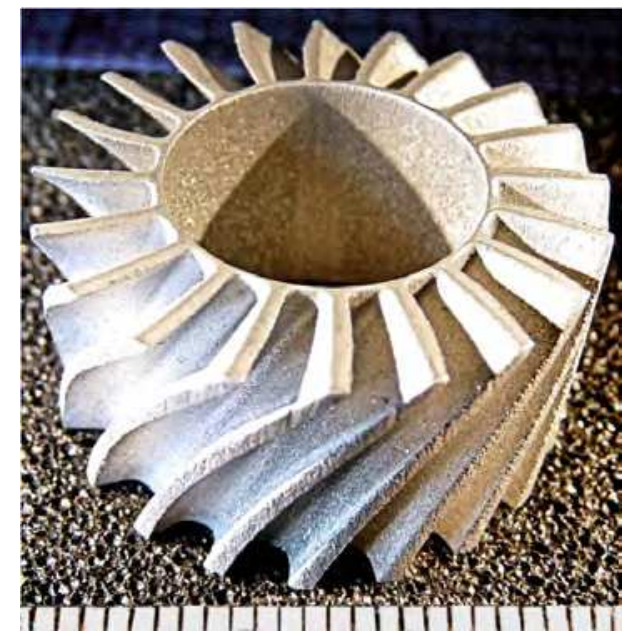

Fig. 21. A-Jet-machined aluminum blisk. Scale: $\mathrm{mm}$.

The Intelli-ETCH (patent pending) is an advanced utility of the OMAX Intelli-MAX® software that allows a user to recreate images in various materials. These images are created from standard bitmap files (JPG, TIFF, BMP, etc.). ${ }^{9}$ By taking the brightness levels of an image and converting those levels into machine speeds, 3D features of the images can be etched onto substrates. Figure 22 illustrates an example of an AWJ-etched lizard on an aluminum substrate. The Intelli-ETCH would have great market potential for controlling $\mu \mathrm{AWJ}$ nozzles for use as versatile jewelry/craft making tools.

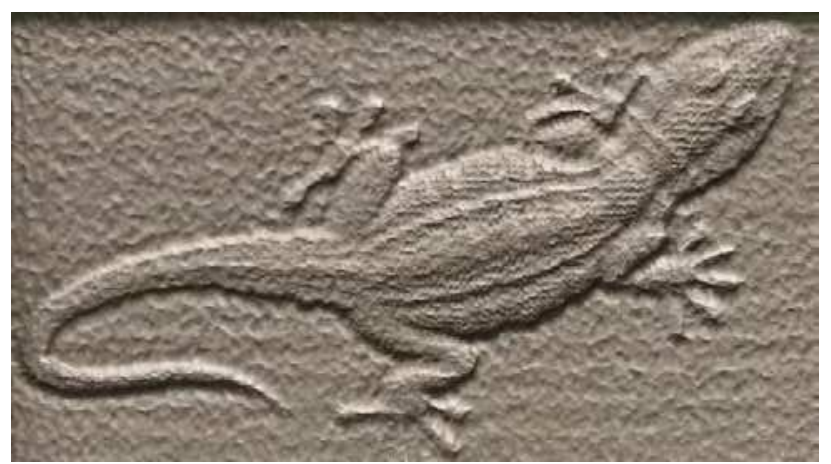

Fig. 22. AWJ-etched lizard on aluminum substrate (Webers et al., 2010) 


\subsection{Non-metal samples}

Several samples made of non-metal materials were machined with the beta and R\&D nozzles to demonstrate the material independence of waterjet technology. The materials included various composites and ceramics with machinability indexes ranging from about 700 to 4 (refer to Fig. 8). Figure 23 shows miniature samples machined from various composites using the 254- $\mu \mathrm{m}$ nozzle (Liu et al., 2010a). The material used for each sample is given in the figure subtitle, along with a number in parentheses that is the thickness of the part in millimeters. Details of small features on the order of $100 \mu \mathrm{m}$ in size remain sharp and crisp. There is no delamination or chipping on the edges. The thickness of the wheel of the smallest bike is about $200 \mu \mathrm{m}$. The carbon fiber (dark) and the epoxy (translucent) layers on the wheels are clearly identifiable in Fig. 23e.

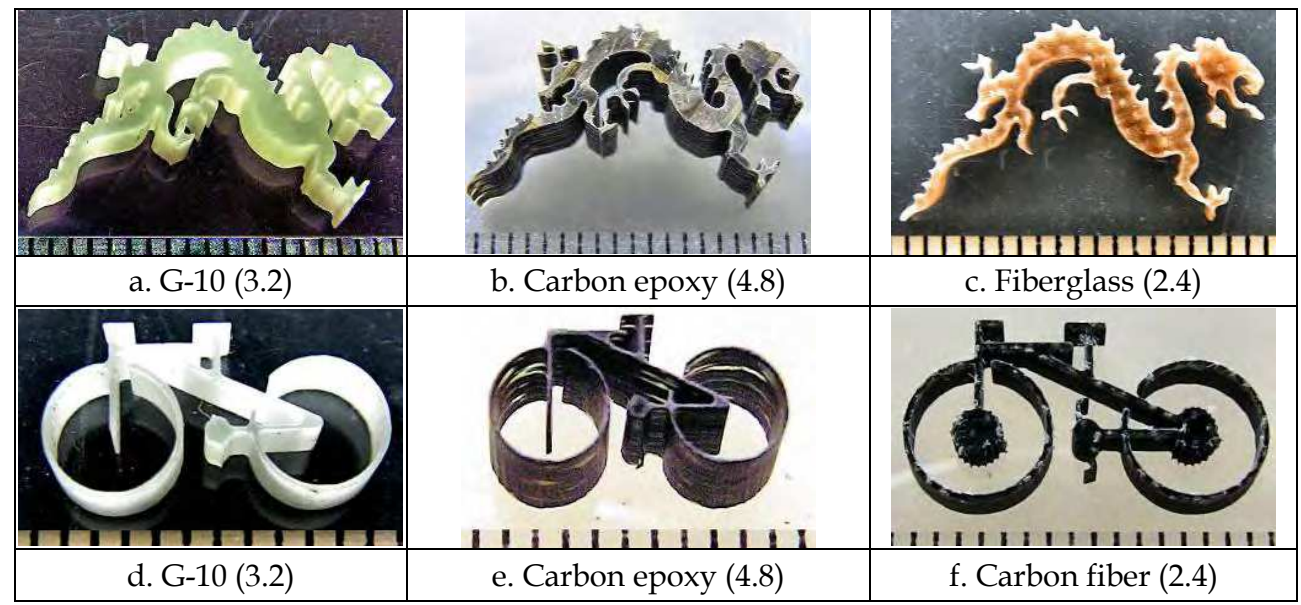

Fig. 23. AWJ-machined miniature composite parts. Numbers in parentheses are thickness of part in mm. Scale: $1 \mathrm{~mm} /$ div. (Liu et al., 2010a)

Figure 24 illustrates features machined with the $254-\mu \mathrm{m}$ nozzle in an alumina plate $0.64 \mathrm{~mm}$ thick $(M \approx 4)$. The sharp and crisp edges of all features are evident.

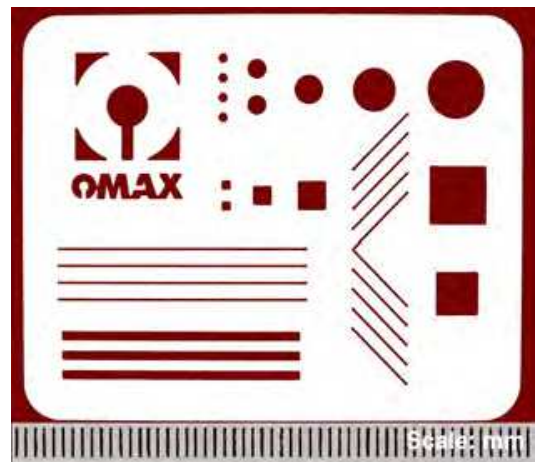

Fig. 24. Features machined with the $254-\mu \mathrm{m}$ nozzle in alumina thin plate (Liu, 2009) 


\subsection{Multi-nozzle platform}

The downsizing of an AWJ nozzle results in a reduction in the flow rate of the waterjet. Depending on the size of the orifice, the number of nozzles that can be supported by a pump increases accordingly. From Fig. 2, a 22.4-kW pump that is capable of supporting one $360-\mu \mathrm{m}$ orifice operating at $380 \mathrm{MPa}$ with a water flow rate of $3.41 / \mathrm{min}$ is capable of supporting four 254- $\mu \mathrm{m}$ nozzles operating at the same pressure. A multi-nozzle platform on which four $254-\mu \mathrm{m}$ nozzles could be mounted was designed, assembled, and tested, as illustrated in Fig. 25. The platform was subsequently delivered for beta testing at a specialty jewelry manufacturing shop. With the nozzles operating in tandem, four identical parts can be machined simultaneously to boost productivity. Among the advantages of using the 254$\mu \mathrm{m}$ nozzle together with 320-mesh garnet are that the amplitude of the striation is small and the finished parts are nearly free of burrs.

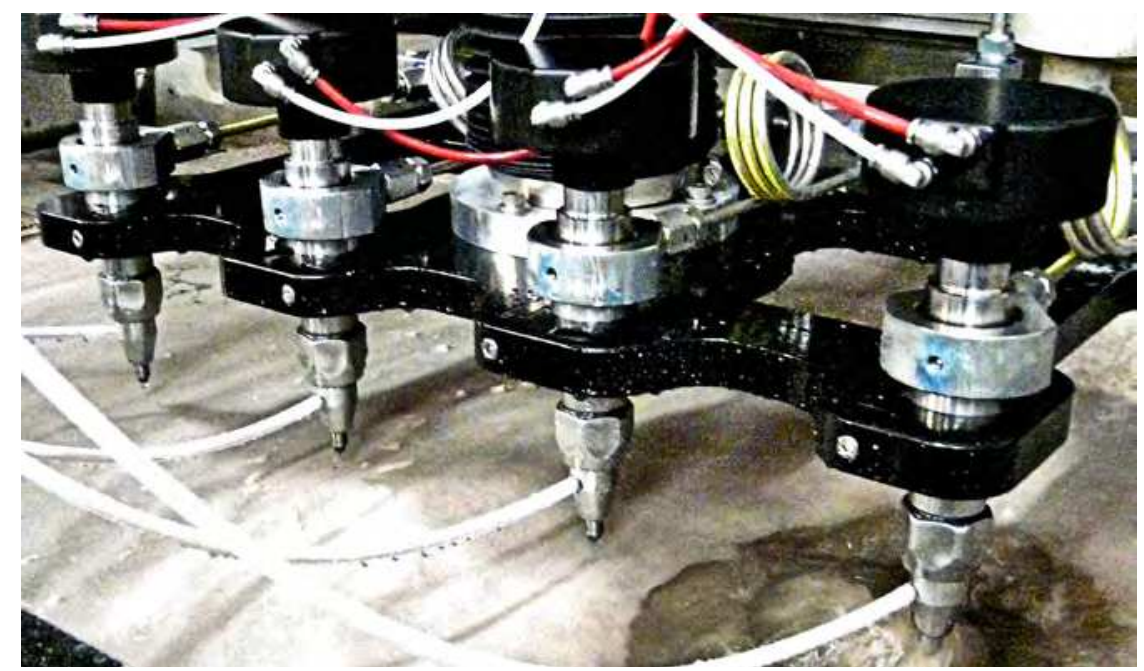

Fig. 25. Four nozzles mounted on a platform for increased productivity (Liu et al., 2011b)

\section{Conclusion}

Waterjet technology has inherent technological and manufacturing merits that make it suitable for machining most materials from macro to micro scales. It has been established as one of the most versatile precision machining tools and has proven amenable to micromachining. This technology has emerged as the fastest growing segment of the overall machine tool industry in the last decade. ${ }^{3}$

The smallest features that can be machined with state-of-the-art commercial AWJ systems are limited to greater than $200 \mu \mathrm{m}$. Further downsizing of AWJ nozzles for machining features less than $200 \mu \mathrm{m}$ has met with considerable challenges, as described in Section 3.1. These challenges, which are due to the complexity of the jet flow as the AWJ flow characteristics change into microfluidics, include nozzle clogging by accumulation of wet abrasives, difficulty in the fabrication of mixing tubes with exit orifices less than $200 \mu \mathrm{m}$, the degradation in the flowability of fine abrasives, and other relevant issues. 
Novel manufacturing and operational processes and ancillary devices have been investigated and developed to meet the above challenges. Miniature beta and R\&D nozzles, without the need for vacuum assist and water flushing, have been assembled and tested to machine miniature samples made of various materials for a broad range of applications. Many of the samples with basic features as small as $100 \mu \mathrm{m}$ were machined to demonstrate the versatility of waterjet technology for low-cost micromanufacturing of components for medical implants/devices and microelectronics, for green energy production systems, and for the post-processing of various micro-nano products.

The advancement and refinement of $\mu \mathrm{AWJ}$ technology continue. Efforts are being made to further downsize $\mu \mathrm{AWJ}$ nozzles for machining features around 100 and $50 \mu \mathrm{m}$. The goal is to commercialize a $\mu \mathrm{AWJ}$ system by integrating $\mu \mathrm{AWJ}$ nozzles with a low-cost, low-power, high-pressure pump and a precision small-footprint X-Y traverse. A host of accessories are already available to be downsized for facilitating 3D meso-micro machining.

\section{Acknowledgment}

This work was supported by an OMAX R\&D fund and NSF SBIR Phase I and II Grants \#0944229 and \#1058278. A part of the work was supported by U. S. Pacific Northwest National Laboratory (PNNL) under Technology Assistance Program (TAP) Agreements: 0729, 08-02, 09-02, and 10-02. Any opinions, findings, and conclusions or recommendations expressed in this material are those of the authors and do not necessarily reflect the views of the NSF and PNNL. Contributions from research institutes and industrial partners by furnishing sample materials and part drawings and by evaluating AWJ-machined parts are acknowledged. Collaborators include but are not limited to Microproducts Breakthrough Institute (MBI), MIT Precision Engineering Research Group, Ryerson University, and several OMAX's customers and suppliers. The authors would like to thank their colleagues at OMAX for reviewing the article and providing us with constructive feedback.

\section{References}

Bachelor, G. K. (1967). An Introduction to Fluid Dynamics, Cambridge University Press, ISBN 0521663962.

Begg, N. (2011). Blind Transmembrane Puncture Access: Design and Development of a Novel Laparoscopic Trocar and Blade Retraction Mechanism, Master Thesis, Mechanical Engineering Department, MIT, pp. 103.

Chen, W.-L. \& Geskin, E. S. (1990). Measurements of the Velocity of Abrasive Waterjet by the Use of Laser Transit Anemometer, Proceedings of 10th International Symposium on Jet Cutting Technology, BHRG Fluid Engineering, Amsterdam, Netherlands, October 3-November 2, pp. 23-36, 1990.

Haerle, F.; Champy, M., \& Terry, B. (Ed) (2009). Atlas of Craniomaxillofacial Osterosynthesis: Microplates, Miniplates, and Screws, 2nd Ed., Thieme, New York, pp. 225.

Hashish, M. (2008). Abrasive-Waterjet Machining of Composites, Proceedings 2009 Amererican WJTA Conference and Exposition, Houston, TX, August 18-20. 
Henning, A.; Miles, P., Stang, D., (2011a). Efficient Operation of Abrasive Waterjet Cutting in Industrial Applications, Proceedings of 2011 WJTA-IMCA Conference $\mathcal{E}$, Houston, Texas, September 19-21.

Henning, A.; Liu, H.-T., \& Olsen, C. (2011b). Economic and Technical Efficiency of High Performance Abrasive Waterjet Cutting, to appear in ASME Journal of Pressure Vessel E Piping.

Jiang, S.; Popescu, R., Mihai, C., \& Tan, K., (2005). High Precision and High Power ASJ Singulations for Semiconductor Manufacturing, Proceedings of 2005 WJTA Conference and exposition., Houston, Texas, August 21-23, Paper 1A-3.

Lamb, H. (1993). Hydrodynamics (6 $6^{\text {th }}$ Ed.). Cambridge University Press, ISBN 9780521458689.

Liu, H.-T. (1998). Near-Net Shaping of Optical Surfaces with Abrasive Suspension Jets, Proceedings of $14^{\text {th }}$ International Conference on Jetting Technology, Brugge, Belgium, September 21-23, pp. 285-294.

Liu, H.-T. (2010). Waterjet Technology for Machining Fine Features Pertaining to MicroMachining, Journal of Manufacturing Processes, Vol.12, No.1, pp. 8-18. (doi:10.1016/ j.jmapro.2010.01.002).

Liu, H.-T. \& McNiel, D. (2010). Versatility of Waterjet Technology: from Macro and Micro Machining for Most Materials, Proceedings of 20th International Conference on Water Jetting, October 20-22, Graz, Austria.

Liu, H.-T. \& Schubert, E. (2010). Piercing and/or Cutting Devices for Abrasive Waterjet Systems and Associated Systems and Methods, U. S. Provisional Patent Application \#612348007.US.

Liu, H.-T.; Hovanski, Y., \& Dahl, M. E. (2011a). Machining of Aircraft Titanium with Abrasive-Waterjets for Fatigue Critical Applications, to appear in ASME Journal of Pressure Vessel E Piping

Liu, H.-T.; Schubert E., and McNiel, D. (2011b). $\mu$ AWJ Technology for Meso-Micro Machining, Proceedings of 2011 WJTA-IMCA Conference and Exposition., Houston, September 19-21.

Liu, H.-T.; Miles, P., \& Veenhuizen, S. D. (1998). CFD and Physical Modeling of UHP AWJ Drilling, Proceedings of $14^{\text {th }}$ International Conference on Jetting Technology, Brugge, Belgium, September 21-23, pp. 15-24.

Liu, H.-T.; Hovanski, Y., Dahl, M. E. \& Zeng, J. (2009a). Applications of Abrasive-Waterjets for Machining Fatigue-Critical Aerospace Aluminum Parts, Proceedings of ASME PVP2009 Conference, Prague, Czech, July 26-30.

Liu, H.-T.; Gnäupel-Herold, T., Hovanski, Y., \& Dahl, M. E. (2009b). Fatigue Performance Enhancement of AWJ-Machined Aircraft Aluminum with Dry-Grit Blasting, Proceedings 2009 American WJTA Conference, Houston, Texas, August 18-20.

Liu, H.-T.; Hovanski, Y., Caldwell, D. D., \& Williford, R. E. (2008a). Low-Cost Manufacturing of Flow Channels with Multi-Nozzle Abrasive-Waterjets: A Feasibility Investigation, Proceedings of $19^{\text {th }}$ International Conference on Water Jetting, Nottingham, UK: October, 15-17. 
Liu, H.-T.; Schubert, E., McNiel, D., \& Soo K. (2010a). Applications of Abrasive-Waterjets for Precision Machining of Composites, Proceedings of SAMPE 2010 Conference and Exhibition, May 17-20, Seattle, Washington, USA.

Liu, H.-T., Schubert E., and McNiel, D. (2010b) “Development of Micro Abrasive-Waterjet Technology," SciTopics, October, pp. 4 (http://www.scitopics.com/Development_ of_Mirco_Abrasive_Waterjet_Technology.html) (8 August 2011).

Liu, L. X.; Marziano, I., Bentham, A .C., Litster, J. D., White, E. T., \& Howes, T. (2008b). Effect of Particle Properties on the Flowability of Ibuprofen Powders, International Journal of Pharmerceutical. Oct 1; 362(1-2): pp. 109-17. Epub 2008 Jul 4.

Miller, D. S. (2005). New Abrasive Waterjet Systems to Complete with Lasers, Proceedings of 2005 WJTA Conference and exposition, Houston, Texas, August 21-23, Paper 1A-1.

Miller, D.; Claffey, S., \& Grove, T. (1996). Technology Package for Abrasive Waterjets, BHR Croup Limited.

Momber, A. W. \& Kovacevic, R. (1998). Principles of Abrasive Water Jet Machining, SpringerVerlag, Berlin.

Olsen, J. H. (2009). Limits to the Precision of Abrasive Jet Cutting, Proceedings of the 9th Pacific Rim International Conference on Water Jetting Technology, Koriyama, Japan, November 20-23, Invited Paper

Olsen, J. H. (1996). Motion Control with Precomputation, U.S. Patent No. 5,508,596, April.

Olsen, J. H. (2005). Automated Fluid-Jet Tilt Compensation of Lag and Taper, U. S. Patent No. 6,922,605, July.

Roth, P.; Looser, H., Heiniger, K. C., \& Buhler, S. (2005). Determination of Abrasive Particle Velocity Using Laser-Induced Fluorescence and Particle Tracking Methods in Abrasive Waterjets, Proceedings of 2005 WJTA Conference and exposition., Houston, Texas, August 21-23, Paper 3A-2

Smith, R. W.; Hirshberg, M. H., \& Manson, S. S. (1967). Fatigue Behavior of Materials under Strain Cycling in Low and Intermediate Life Range, NASA Technical Note D-1574, NASA Lewis Research Center, pp. 25.

Stevenson, A. N. J. \& Hutchings, I. M. (1995). Scaling Laws for Particle Velocity in the GasBlast Erosion Test, Wear, 181-183, pp. 56-62.

Swanson, R. K.; Kilman, M., Cerwin, S., \& Tarver, W. (1987). Study of Particle Velocities in Water Driven Abrasive Jet Cutting, Proceedings of 4th U.S. Water Jet Conference, ASME, Berkeley, CA, August 26-28, pp. 103-107

Trieb, F. H. (2010). Waterjet Cutting in Austria - History and Actual Status, Keynote Speech, Proceedings of 20th International Conference on Water Jetting, Graz, Austria, October 20-22, pp. 3-17.

Trimble, A. Z. (2011). Vibration Energy Harvesting of Wide-Band Stochastic Inputs with Application to an Electro-Magnetic Rotational Energy Harvester, Ph.D. Dissertation, Mechanical Engineering Department, MIT, June, pp. 207.

Yu, W.; Muteki, K., Zhang, L. \& Kim, G. (2011). Prediction of Bulk Power Flow Performance Using Comprehensive Particle Size and Particle Shape Distribution, Journal of Pharmaceutical Sciences., Vol.100, No.1, January (also DOI 10.1002/jps.22254) 
Webers, N.; Olsen, C., Miles, P. \& Henning, A. (2010) Etching 3D Patterns with Abrasive Waterjets, Proceedings of 20th International Conference on Water Jetting, Graz, Austria, October 20-22, pp. 51-63.

Zeng, J. \& Kim, T. J. (1995), Machinability of Engineering Materials in Abrasive Water Jet Machining, International Journal of Water Jetting Technology, Vol.2, No.2, pp. 103-110. 


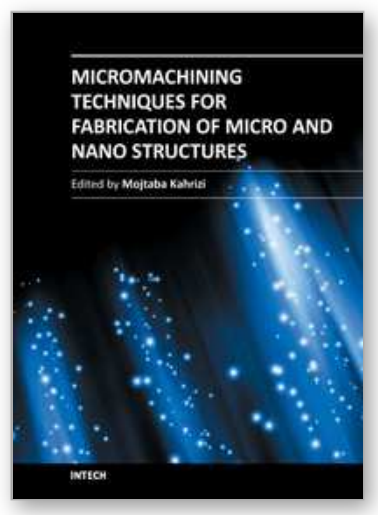

\section{Micromachining Techniques for Fabrication of Micro and Nano Structures}

Edited by Dr. Mojtaba Kahrizi

ISBN 978-953-307-906-6

Hard cover, 300 pages

Publisher InTech

Published online 03, February, 2012

Published in print edition February, 2012

Micromachining is used to fabricate three-dimensional microstructures and it is the foundation of a technology called Micro-Electro-Mechanical-Systems (MEMS). Bulk micromachining and surface micromachining are two major categories (among others) in this field. This book presents advances in micromachining technology. For this, we have gathered review articles related to various techniques and methods of micro/nano fabrications, like focused ion beams, laser ablation, and several other specialized techniques, from esteemed researchers and scientists around the world. Each chapter gives a complete description of a specific micromachining method, design, associate analytical works, experimental set-up, and the final fabricated devices, followed by many references related to this field of research available in other literature. Due to the multidisciplinary nature of this technology, the collection of articles presented here can be used by scientists and researchers in the disciplines of engineering, materials sciences, physics, and chemistry.

\section{How to reference}

In order to correctly reference this scholarly work, feel free to copy and paste the following:

H.-T. Liu and E. Schubert (2012). Micro Abrasive-Waterjet Technology, Micromachining Techniques for Fabrication of Micro and Nano Structures, Dr. Mojtaba Kahrizi (Ed.), ISBN: 978-953-307-906-6, InTech, Available from: http://www.intechopen.com/books/micromachining-techniques-for-fabrication-of-micro-andnano-structures/-micro-abrasive-waterjet-technology

\section{INTECH}

open science | open minds

\section{InTech Europe}

University Campus STeP Ri

Slavka Krautzeka 83/A

51000 Rijeka, Croatia

Phone: +385 (51) 770447

Fax: +385 (51) 686166

www.intechopen.com

\section{InTech China}

Unit 405, Office Block, Hotel Equatorial Shanghai

No.65, Yan An Road (West), Shanghai, 200040, China

中国上海市延安西路65号上海国际贵都大饭店办公楼 405 单元

Phone: +86-21-62489820

Fax: $+86-21-62489821$ 
(C) 2012 The Author(s). Licensee IntechOpen. This is an open access article distributed under the terms of the Creative Commons Attribution 3.0 License, which permits unrestricted use, distribution, and reproduction in any medium, provided the original work is properly cited. 